\title{
Should Reversible Convective Inhibition be Used when Determining the Inflow Layer of a Convective Storm?
}

\author{
Shawn S. Murdzek, ${ }^{\mathrm{a}}$ Paul M. Markowski, ${ }^{\mathrm{a}}$ Yvette P. Richardson, ${ }^{\mathrm{a}}$ And Matthew R. Kumjian ${ }^{\mathrm{a}}$ \\ ${ }^{a}$ Department of Meteorology and Atmospheric Science, The Pennsylvania State University, University Park, Pennsylvania
}

(Manuscript received 10 March 2021, in final form 2 July 2021)

\begin{abstract}
Convective inhibition (CIN) is one of the parameters used by forecasters to determine the inflow layer of a convective storm, but little work has examined the best way to compute CIN. One decision that must be made is whether to lift parcels following a pseudoadiabat (removing hydrometeors as the parcel ascends) or reversible moist adiabat (retaining hydrometeors). To determine which option is best, idealized simulations of ordinary convection are examined using a variety of base states with different reversible CIN values for parcels originating in the lowest $500 \mathrm{~m}$. Parcel trajectories suggest that ascent over the lowest few kilometers, where CIN is typically accumulated, is best conceptualized as a reversible moist adiabatic process instead of a pseudoadiabatic process. Most inflow layers do not contain parcels with substantial reversible CIN, despite these parcels possessing ample convective available potential energy and minimal pseudoadiabatic CIN. If a stronger initiation method is used, or hydrometeor loading is ignored, simulations can ingest more parcels with large amounts of reversible CIN. These results suggest that reversible CIN, not pseudoadiabatic CIN, is the physically relevant way to compute $\mathrm{CIN}$ and that forecasters may benefit from examining reversible CIN instead of pseudoadiabatic CIN when determining the inflow layer.
\end{abstract}

KEYWORDS: Convective storms/systems; Updrafts/downdrafts; Mesoscale forecasting

\section{Introduction}

To forecast hazards associated with a convective storm, it is useful to know the properties of air parcels being ingested by the storm. For example, to predict whether a storm will produce a tornado, forecasters often examine inflow soundings for characteristics known to be favorable for tornadic storms, such as low lifted condensation levels (LCL), large amounts of low-level storm-relative helicity (SRH), and large vertical wind shear, which is typically assessed in terms of the magnitude of a vector wind difference (e.g., Rasmussen and Blanchard 1998; Thompson et al. 2003). The idea is that these inflow soundings are measuring the properties of low-level air that will ultimately be ingested by the storm and influence its behavior. As pointed out by Thompson et al. (2007) and Nowotarski et al. (2020), parameters such as SRH and vertical wind shear are often tied to arbitrary levels (e.g., $0-1$ or $0-3 \mathrm{~km}$ ), which may not be representative of the inflow layer of a particular storm. For example, Thompson et al. (2007) present a case for which an inflow sounding had $356 \mathrm{~m}^{2} \mathrm{~s}^{-2}$ of $0-3-\mathrm{km} \mathrm{SRH}$, but most of this SRH was confined to a statically stable layer near the surface. Parcels in this statically stable layer likely did not participate in the storm updraft, so the actual SRH experienced by the storm was likely significantly less than the fixedlayer value.

In an attempt to isolate the layer that contains air parcels that participate in the updraft of a convective storm and, therefore, influence its characteristics, Thompson et al. (2007) developed the effective inflow layer (EIL). The EIL uses convective available potential energy (CAPE) and convective inhibition (CIN) thresholds to predict which parcels will be

Corresponding author: Shawn S. Murdzek, smurdzek@psu.edu ingested by a storm, where CAPE is the integrated positive parcel buoyancy above the level of free convection (LFC) and CIN is the integrated negative parcel buoyancy below the LFC. By identifying the layer from which parcels destined for the updraft originate, characteristics of those parcels can be determined. Thompson et al. (2007) found that SRH computed over the EIL (denoted ESRH) was a better discriminator between significantly tornadic and nontornadic supercells than either the $0-1$ - or $0-3-\mathrm{km} \mathrm{SRH} .{ }^{1}$ Although Thompson et al. (2007) could not determine whether the parcels within the identified EIL actually entered the observed storms in their database, recent work by Nowotarski et al. (2020) suggests that the thresholds of CAPE $\geq 100 \mathrm{~J} \mathrm{~kg}^{-1}$ and CIN $\leq 250 \mathrm{~J} \mathrm{~kg}^{-1}$ proposed by Thompson et al. (2007) for the EIL are skillful in predicting the updraft parcel origin height for simulated supercell storms.

One ambiguity with the EIL as defined by Thompson et al. (2007) is that there are several different ways to compute CAPE and CIN, with some of these methods being less physical than others. For example, Doswell and Rasmussen (1994) point out that CAPE computed using a virtual temperature correction is more physical because it includes water vapor in the parcel buoyancy calculation. Another choice is whether to compute CAPE and CIN using pseudoadiabatic or reversible moist adiabatic parcel ascent (hereafter reversible parcel ascent).

\footnotetext{
${ }^{1}$ Coffer et al. $(2019,2020)$ recently demonstrated that using SRH integrated over a layer shallower than $1 \mathrm{~km}$ (e.g., $0-500$ or 0-100 m) better discriminates between significantly tornadic and severe nontornadic supercells compared to ESRH, though as pointed out by Nowotarski et al. (2020), EIL-based parameters may still be useful in predicting other storm hazards (e.g., hail).
} 
RUC Analysis: 15 June 20110300 UTC at $\left(39.63^{\circ} \mathrm{N}, 92.23^{\circ} \mathrm{W}\right)$
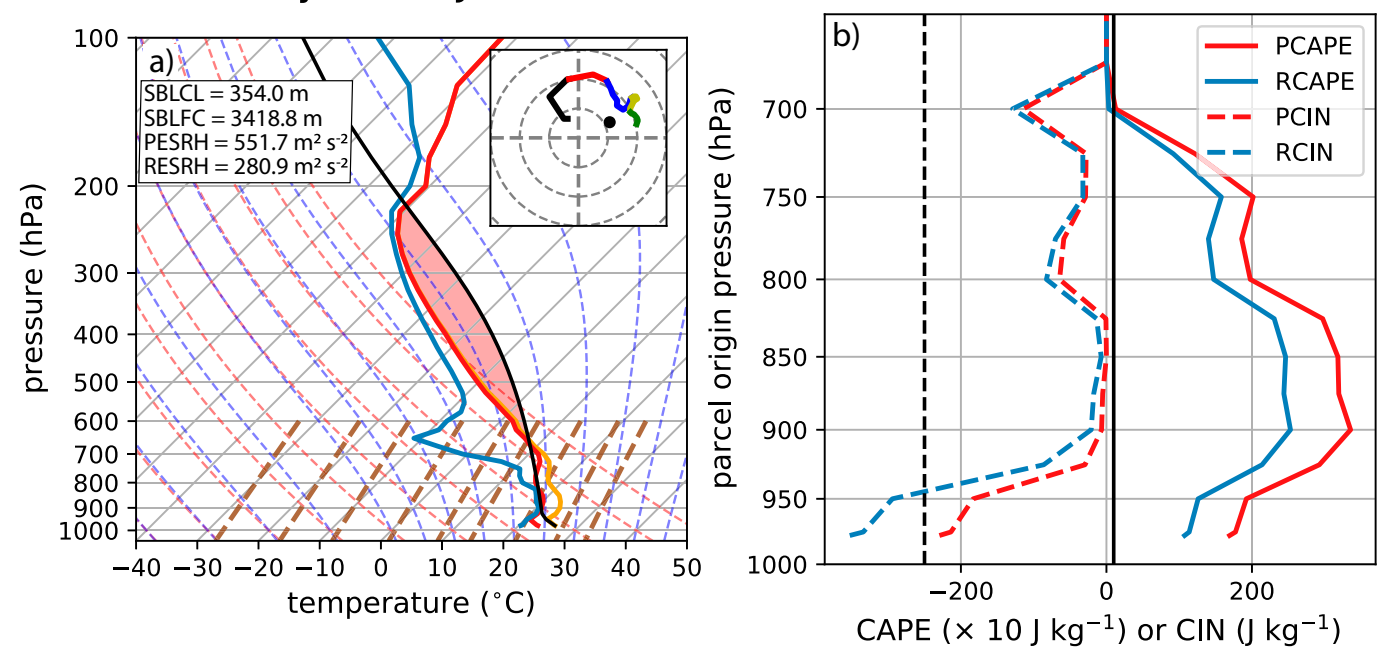

FIG. 1. Rapid Update Cycle (RUC) analysis sounding from northeastern Missouri on 15 Jun 2011. (a) Skew $T$-log $p$ diagram where the solid red, blue, orange, and black lines correspond to the temperature, dewpoint, virtual temperature, and surface-based parcel virtual temperature (following pseudoadiabatic parcel ascent) profiles, respectively. Shaded red area is proportional to the PCAPE, and the surface-based LCL (SBLCL), surface-based pseudoadiabatic LFC (SBLFC), ESRH using PCAPE and PCIN (PESRH), and ESRH using RCAPE and RCIN (RESRH) are listed. Inset plot shows the hodograph (range rings every $10 \mathrm{~m} \mathrm{~s}^{-1}$ ) with the colored line segments denoting the winds from 0 to $0.5 \mathrm{~km}$ (black), 0.5 to $1 \mathrm{~km}$ (red), 1 to $3 \mathrm{~km}$ (blue), 3 to $6 \mathrm{~km}$ (yellow), and 6 to $9 \mathrm{~km}$ (green). Black dot denotes the Bunkers et al. (2000) right-mover storm motion. (b) Pseudoadiabatic and reversible CAPE and CIN values for parcels lifted from various initial pressures. The solid and dashed black lines denote the CAPE and CIN thresholds typically used for the effective inflow layer (CAPE $\geq 100 \mathrm{~J} \mathrm{~kg}^{-1}$ and CIN $\leq 250 \mathrm{~J} \mathrm{~kg}^{-1}$ ), respectively. Note that the CAPE values in (b) are reduced by a factor of 10 and CIN values are negative for clarity.

In pseudoadiabatic parcel ascent, hydrometeors are removed from a parcel as soon as they form, whereas in reversible parcel ascent, all hydrometeors are retained (Emanuel 1994). The presence of hydrometeors within a parcel during reversible ascent has two impacts on parcel buoyancy. First, the presence of hydrometeors increases the heat capacity of a parcel, causing the parcel temperature to decrease less rapidly with height and therefore increase parcel buoyancy (compared to pseudoadiabatic parcel ascent). Second, the presence of hydrometeors contributes an additional negative term to buoyancy owing to hydrometeor loading. Table 4.2 from Emanuel (1994) indicates that the second effect is typically larger than the first (at least below $\sim 150 \mathrm{hPa}$ ), so parcels lifted reversibly tend to be less buoyant than those lifted pseudoadiabatically. As a result, pseudoadiabatic CAPE (PCAPE) is larger than reversible CAPE (RCAPE) and pseudoadiabatic CIN (PCIN) is smaller in magnitude than reversible CIN (RCIN).

The differences between PCIN and RCIN can be quite large in the real atmosphere, particularly in environments with a low LCL and a high LFC. A low LCL and high LFC results in a deep layer where parcels are negatively buoyant and saturated. As a parcel rises between the LCL and LFC, hydrometeors form, which makes the RCIN more negative owing to hydrometeor loading (PCIN, on the other hand, is not impacted). A deeper LCL-to-LFC layer exacerbates the difference between RCIN and PCIN because more hydrometeors can form and these hydrometeors need to be carried over a greater depth before the parcel becomes positively buoyant. An example of a low-LCL, high-LFC environment is shown in Fig. 1, which comes from a Rapid Update Cycle (RUC; Benjamin et al. 2004) analysis on 15 June 2011 in northeastern Missouri ahead of multiple severe thunderstorms that produced hail, damaging winds, and an EF0 tornado according to Storm Data (NCDC 2011). As shown in Fig. 1b, the differences between PCIN and RCIN exceed $100 \mathrm{~J} \mathrm{~kg}^{-1}$ for parcels originating below $\sim 940 \mathrm{hPa}$, which results in different EIL depths. If pseudoadiabatic parameters are used with the CAPE and CIN thresholds from Thompson et al. (2007), the EIL would stretch from the surface to $700 \mathrm{hPa}$, which is a depth of $2862 \mathrm{~m}$. If reversible parameters are used, the EIL would be between 925 and $725 \mathrm{hPa}$ (a depth of $2087 \mathrm{~m}$ ) owing in part to the larger (in magnitude) RCIN compared to PCIN in the lowest levels of the sounding. These differences in EIL depth can lead to large differences in environmental parameters commonly used to forecast convective hazards, such as ESRH. When using PCAPE and PCIN, ESRH is $551.7 \mathrm{~m}^{2} \mathrm{~s}^{-2}$, whereas when RCAPE and RCIN are used, ESRH drops to $280.9 \mathrm{~m}^{2} \mathrm{~s}^{-2}$, a reduction by almost a factor of 2. This large difference is primarily the result of strong $0-500$ $m$ environmental vertical wind shear, which is excluded from the EIL when using reversible CIN (Fig. 1). Given that large differences between PCIN and RCIN are more likely in low-LCL, high-LFC environments, differences between the EIL diagnosed using pseudoadiabatic versus reversible parameters are likely largest in capped environments or in the southeastern 
United States where LCLs are typically lower (e.g., Thompson et al. 2013).

Given that the differences between pseudoadiabatic versus reversible CAPE and CIN have the potential to change the EIL by over three-quarters of a kilometer, it would be helpful to know which method is more physical. As pointed out by Bohren and Albrecht (1998) and McCaul et al. (2005), parcel ascent in the real atmosphere likely falls somewhere between the pseudoadiabatic and reversible extremes. Therefore, it is unclear whether pseudoadiabatic or reversible CAPE and CIN values should be evaluated by forecasters trying to determine the behavior of a thunderstorm. In the context of midlatitude convective storms (which is the focus of this article), only two studies appear to have explored this issue: McCaul et al. (2005) and Kirkpatrick et al. (2009). McCaul et al. (2005) found that storms in environments with less precipitable water had stronger peak updraft speeds compared to storms in environments with more precipitable water, which was partly attributed to the increased hydrometeor loading in the high-precipitable water storm. This difference in peak updraft speed could be anticipated by examining the RCAPE values of the two environments. Along a similar vein, Kirkpatrick et al. (2009) found that RCAPE is more skillful than PCAPE at predicting the maximum vertical velocities during the second hour in their set of 216 supercell simulations with different base-state environments. When combined with other environmental predictors (e.g., height of maximum buoyancy, shear, LCL), however, multiple linear regressions using PCAPE are more skillful at predicting maximum vertical velocities than multiple linear regressions using RCAPE. ${ }^{2}$ In light of these results, it is unclear if PCAPE or RCAPE is a better predictor of updraft strength, which is not surprising because, as mentioned earlier, parcel ascent through the middle troposphere likely lies somewhere between a pseudoadiabat and a reversible moist adiabat.

The differences between pseudoadiabatic and reversible parcel ascent have received somewhat more scrutiny in research related to tropical convection. Early studies by Betts (1982), Xu and Emanuel (1989), and Cohen and Frank (1989) suggest that the mean tropical atmosphere is nearly neutrally buoyant to undiluted parcel ascent along a reversible moist adiabat for parcels originating near cloud base, even though the PCAPE may be positive. This does not mean, however, that tropical convection is best conceptualized as undiluted reversible parcel ascent. During actual convection, entrainment should also be considered (e.g., Wei et al. 1998), and as mentioned above, some hydrometeor fallout would be expected, which would cause parcel ascent to deviate from a reversible moist adiabat. Even among these studies, however, the focus tends to be concentrated on CAPE values and not CIN, which is the focus of this article.

\footnotetext{
${ }^{2}$ In addition to buoyancy, supercellular updrafts also receive a contribution from vertical dynamic accelerations that are related to supercell rotation (e.g., Weisman and Klemp 1984; Peters et al. 2019). Neither PCAPE nor RCAPE includes these dynamic effects.
}

Following the recommendations of Doswell and Rasmussen (1994), CAPE and CIN values used by forecasters in the midlatitudes ${ }^{3}$ are almost always computed using pseudoadiabatic parcel ascent. One benefit to using PCAPE and PCIN is that pseudoadiabats can be easily displayed on a skew $T-\log p$ diagram, which allows for PCAPE and PCIN to be represented graphically (Emanuel 1994). Reversible moist adiabats, on the other hand, cannot be easily drawn on a skew $T-\log p$ diagram, because, for a given saturation point (i.e., the temperature and pressure of a saturated parcel), there can be any number of reversible moist adiabats depending on the hydrometeor concentration, whereas there is only one pseudoadiabat. Based on the results of Kirkpatrick et al. (2009), there appears to be no obvious benefit to using RCAPE instead of PCAPE when forecasting midlatitude convective storms.

But what about PCIN versus RCIN? CIN is accumulated during the first stage of parcel ascent while the parcel is below the LFC [which is often $<3 \mathrm{~km}$ AGL in severe thunderstorm environments for mixed-layer parcels (Taszarek et al. 2020)], and during this stage, any hydrometeors that happen to form are likely to be small and have smaller fall speeds because they have not had much time to grow (e.g., Lamb and Verlinde 2011). Because of their reduced fall speeds, these hydrometeors are more likely to stay within the parcel. Therefore, parcel ascent may be better represented by a reversible moist adiabat over the lower depths of the troposphere, as suggested by Cohen and Frank (1989). Even if a parcel in the lowest few kilometers is precipitating, it seems plausible that the amount of water being lost by the parcel may be offset by the water gained owing to precipitation from parcels farther aloft. This may result in parcel ascent that better resembles a reversible moist adiabat, at least at low levels.

Based on the preceding discussion, our research questions are as follows:

1) Does parcel ascent in the lowest few kilometers of an ordinary convective storm better follow a pseudoadiabat or a reversible moist adiabat?

2) How does the inflow layer of a storm change if the RCIN of low-level air parcels increases but the PCIN stays approximately constant? Put another way, should the EIL from Thompson et al. (2007) be computed using PCIN or RCIN?

We attempt to answer these questions using idealized numerical simulations of ordinary convective storms. Our focus is on ordinary convective storms in order to remove the additional complexity associated with the strong dynamic updraft forcings that occur in convective storms in highly sheared environments (e.g., Weisman and Klemp 1984), and because simulations of ordinary convection are computationally cheaper compared to stronger forms of convection

\footnotetext{
${ }^{3}$ The "midlatitude" qualifier is used here because other methods of computing CAPE may be more applicable in other regions. For example, to compute CAPE within tropical cyclones, Molinari et al. (2012) recommends using reversible parcel ascent with corrections that account for some entrainment and the extra heating provided by the freezing of hydrometeors.
} 
(e.g., supercells). An overview of the simulation setup and analysis methods is outlined in section 2. The first question is addressed using parcel trajectories in section 3, while the second question is addressed using passive tracers in section 4. A summary of our primary findings is given in section 5 .

\section{Methods}

\section{a. Numerical model overview}

Ordinary convection is simulated using Cloud Model version 1, release 19.8 (CM1; Bryan and Fritsch 2002; Bryan and Morrison 2012), which evolves the atmosphere by integrating the filtered Navier-Stokes equations forward in time. The model spatial domain is $120 \mathrm{~km} \times 120 \mathrm{~km} \times 20 \mathrm{~km}$ with $500-\mathrm{m}$ grid spacing in the horizontal and $100-\mathrm{m}$ grid spacing in the vertical in the lowest $4 \mathrm{~km}$. A constant vertical grid spacing of $500 \mathrm{~m}$ is used above $16 \mathrm{~km}$ and the vertical grid is stretched between 4 and $16 \mathrm{~km}$. Because the focus here is only on the initial convective cell and not any secondary convection that may result, each simulation is only run for $1 \mathrm{~h}$ using a large time step that is initially set to $2 \mathrm{~s}$ with the adaptive time stepping option in CM1 enabled. The slower wind speeds in these simulations compared to other forms of convection (e.g., supercells) allows for the large time step to be increased while still maintaining numeric stability, so for most of the integration time, the adaptive time stepping procedure adjusted the large time step to be $4 \mathrm{~s}$. The lateral boundary conditions are open-radiative, the top and bottom boundary conditions are free slip, and a Rayleigh-damping layer is applied between $15 \mathrm{~km}$ above ground level (AGL) and the model lid. To create realistic convective cells, pseudorandom potential temperature perturbations taken from a uniform distribution ranging from -0.05 to $+0.05 \mathrm{~K}$ are added to the initial model base state. Owing to the short integration time and the desire to remove additional complexity, surface fluxes, radiation, and the Coriolis acceleration are all turned off. The model configuration is summarized in Table 1.

Three microphysics parameterizations are used in these simulations. The reasoning behind using multiple microphysics parameterizations is because the behavior of hydrometeors helps control whether a process is best described as pseudoadiabatic or reversible moist adiabatic. If the microphysics parameterization grows hydrometeors rapidly and uses fast fall speeds, then parcel ascent may be best conceptualized as pseudoadiabatic. If all hydrometeor fall speeds are near zero, then parcel ascent will likely resemble a reversible moist adiabatic process. The majority of the simulations use the Morrison et al. (2005, 2009) twomoment microphysics scheme with hail as the rimed ice species. Given that we are focusing on the lowest few kilometers of parcel ascent, we expect warm rain processes to dominate, so a series of simulations are performed using the Morrison microphysics scheme with the autoconversion from cloud water to rain increased by a factor of 10 (these experiments are denoted AUT). Autoconversion is altered
TABLE 1. CM1 configuration.

\begin{tabular}{lc}
\hline \multicolumn{1}{c}{ Parameter } & Value \\
\hline $\begin{array}{l}\text { Domain size } \\
\text { Horizontal grid spacing }\end{array}$ & $120 \mathrm{~km} \times 120 \mathrm{~km} \times 20 \mathrm{~km}$ \\
Vertical grid spacing & $500 \mathrm{~m}$ \\
Large time step & $\begin{array}{c}100 \mathrm{~m} \text { below } 4 \mathrm{~km}, \text { stretching to } \\
500 \mathrm{~m} \text { at } 16 \mathrm{~km}\end{array}$ \\
& $\begin{array}{c}\text { Initially } 2 \mathrm{~s}, \text { but } 4 \mathrm{~s} \text { for most of the } \\
\text { integration time }\end{array}$ \\
Lateral boundary conditions & Open-radiative \\
Top and bottom boundary & Free slip \\
conditions & Morrison et al. (2005, 2009) two- \\
Microphysics & moment \\
& Turbulent kinetic energy (TKE) \\
Subgrid-scale turbulence & scheme \\
& None \\
Radiation & None \\
Surface fluxes & None \\
Coriolis acceleration & $300 \mathrm{~s}$ \\
Output frequency &
\end{tabular}

instead of other warm-rain processes because a more rapid transfer of water mass from cloud water to rain would be expected to result in larger, faster-falling hydrometeors, which may cause parcel ascent to be pushed closer to a pseudoadiabat instead of a reversible moist adiabat. Another set of simulations is also performed using the National Severe Storms Laboratory (NSSL) two-moment scheme with predicted graupel and hail densities (Mansell et al. 2010) to see if our results change when using a completely different microphysics scheme.

In addition to the 500-m grid-spacing simulations outlined above, select simulations are also rerun using a smaller domain $(80 \mathrm{~km} \times 80 \mathrm{~km} \times 18 \mathrm{~km})$ and isotropic $100-\mathrm{m}$ grid spacing. All other model configurations are the same between these $100-\mathrm{m}$ simulations and the 500-m simulations. The goal of the $100-\mathrm{m}$ simulations is to determine if the qualitative results presented herein change when the model grid spacing follows the recommendations of Bryan et al. (2003) for simulating convective storms using a large-eddy simulation. As shown in sections 3 and 4 , our qualitative results do not appear to change when a finer grid spacing is used.

\section{b. Base states}

Each CM1 simulation is initialized with a horizontally homogeneous environment with a vertical thermodynamic profile based on the analytic buoyancy profile of McCaul and Weisman (2001). The benefit to using this buoyancy profile is that it allows the user to vary the LCL while holding the CAPE, LFC, vertical buoyancy profile above the LFC, pseudoequivalent potential temperature $\left(\theta_{e p}\right)$ below the LFC, and relative humidity profile above the LFC constant. A total of four thermodynamic base states with LCL $=500$, 1000, 1500, and $2000 \mathrm{~m}$ are used herein (Fig. 2). As discussed in the introduction, increasing the distance between the LCL and LFC greatly alters the RCIN for parcels originating below the LCL, whereas the PCIN of these parcels remains relatively unchanged. Thus, changing the LCL allows us to change RCIN without altering PCIN, which 

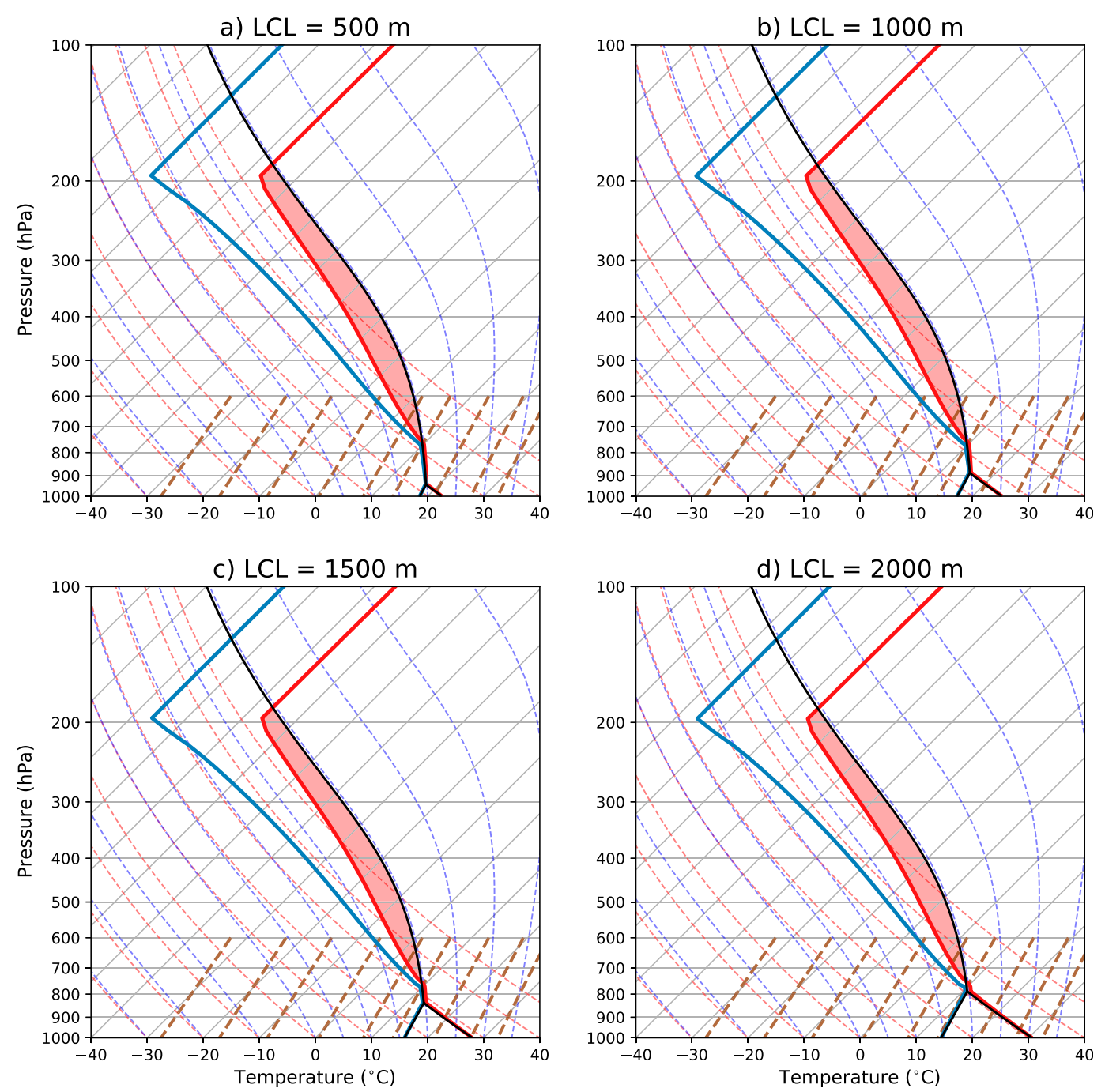

FIG. 2. Thermodynamic base states used for the CM1 simulations with LCL = (a) 500, (b) 1000, (c) 1500, and (d) $2000 \mathrm{~m}$. Solid red, blue, and black lines show the temperature, dewpoint, and surface-based parcel temperature (following pseudoadiabatic parcel ascent) profiles, respectively. The shaded red area is proportional to the PCAPE.

lets us test whether changing the RCIN changes which parcels are ingested into the simulated storms.

The generation of the thermodynamic base states from the buoyancy profile of McCaul and Weisman (2001) is similar to Warren et al. (2017) and is briefly outlined here. First, the planetary boundary layer (PBL) thermodynamic structure is created by selecting a surface temperature, surface pressure, and PBL lapse rate (see Table 2), and then integrating the hydrostatic balance equation upward while holding $\theta_{e p}$ constant at $335 \mathrm{~K}$. The PBL depth is fixed at $2300 \mathrm{~m}$ for all base states and the layer between the LCL and PBL top is filled with a constant $-\theta_{e p}$ layer with a lapse rate that is $0.1 \mathrm{~K} \mathrm{~km}^{-1}$ less than the moist adiabatic lapse rate (i.e., the temperature profile has slight conditional stability). This is similar to the LCL $\neq$ LFC base states from McCaul and Cohen (2002) as well as the 1000-700-hPa layer from the RUC sounding in Fig. 1a. Second, the free troposphere thermodynamic profile is found by computing the virtual temperature profile for a surface-based parcel (assuming pseudoadiabatic parcel ascent) and then computing the environmental virtual temperature profile using the analytic buoyancy profile in Eq. (A1) from McCaul and Weisman (2001) with $E=2000 \mathrm{~J} \mathrm{~kg}^{-1}$, $m=2.2$, and $H=12500 \mathrm{~m}$. Similar to Warren et al. (2017), the environmental relative humidity varies linearly from the PBL top to $10 \%$ at the tropopause $(12000 \mathrm{~m})$. Third, the thermodynamic profile above the tropopause is constructed using constant temperature and relative humidity profiles. Following the appendix of Warren et al. (2017), the thermodynamic profile above the PBL is computed iteratively so that the computed PCAPE is between 1999.5 and $2000.5 \mathrm{~J} \mathrm{~kg}^{-1}$. The thermodynamic profile must be computed iteratively for two reasons: 1) the buoyancy profile used in the free troposphere is truncated at the tropopause, causing the PCAPE to be less than $E$ (Warren et al. 2017), and 2) a maximum lapse 
TABLE 2 . Thermodynamic base-state parameters: $p_{\text {sfc }}$ and $T_{\text {sfc }}$ refer to the surface pressure and temperature, respectively. LCL, LFC, and equilibrium level (EL) are computed for a surface-based parcel following pseudoadiabatic ascent using the base states interpolated to the CM1 grid (computations are performed using the getcape subroutine in CM1, which includes the virtual temperature correction). In the text, all LCLs are rounded to the nearest hundred meters. CAPE and CIN values are presented in Fig. 3.

\begin{tabular}{cccccc}
\hline \hline LCL $(\mathrm{m})$ & $\mathrm{LFC}(\mathrm{m})$ & $\mathrm{EL}(\mathrm{m})$ & $p_{\text {sfc }}(\mathrm{hPa})$ & $T_{\text {sfc }}(\mathrm{K})$ & $\begin{array}{c}\text { PBL lapse } \\
\text { rate }\left(\mathrm{K} \mathrm{km}^{-1}\right)\end{array}$ \\
\hline 500 & 2372 & 12469 & 1000 & 295.7 & 9.12 \\
1000 & 2362 & 12471 & 1000 & 298.4 & 9.33 \\
1510 & 2361 & 12477 & 1000 & 301.1 & 9.39 \\
2010 & 2376 & 12483 & 1000 & 303.8 & 9.38 \\
\hline
\end{tabular}

rate of $9.475 \mathrm{~K} \mathrm{~km}^{-1}$ is imposed, which alters the temperature profile after construction and also causes the PCAPE to be less than $E$.

Vertical profiles of CAPE and CIN for parcels lifted both pseudoadiabatically and reversibly ${ }^{4}$ from various levels are shown in Fig. 3. Not surprisingly, RCAPE is lower than PCAPE for parcels originating in the PBL because of hydrometeor loading (Figs. 3a,c). The difference between the RCIN and PCIN for parcels originating in the lowest $500 \mathrm{~m}$ AGL increases as the base state LCL decreases. In fact, RCIN is almost 5 times larger than PCIN for parcels originating in the lowest $500 \mathrm{~m}$ AGL in the LCL $=500$-m base state, whereas the RCIN and PCIN are almost identical for parcels originating in the lowest $500 \mathrm{~m}$ of the LCL $=2000$-m base state (Figs. 3c,d). The primary reason for the large differences between RCIN and PCIN in the LCL $=500-\mathrm{m}$ base state is the same reason as that for the RUC sounding in Fig. 1: a greater distance between the LCL and LFC results in more hydrometeors as well as a greater depth over which those hydrometeors must be lifted, both of which increase the amount of work required to lift a parcel to the LFC. ${ }^{5}$ The depth of the layer with positive PCAPE and RCAPE is approximately constant as the LCL is increased, which means that any differences in the inflow layer between the four base states can be attributed primarily to differences in RCIN (i.e., the inflow layer will be CIN-limited rather than CAPE-limited).

Most of the simulations use base states with no wind in order to remove the additional complexity arising from strong dynamic lifting that occurs when there is vertical wind shear (e.g.,

\footnotetext{
${ }^{4}$ PCAPE and PCIN are computed using the virtual potential temperature whereas RCAPE and RCIN are computed using the density potential temperature with the hydrometeor mixing ratio set to the adiabatic liquid water mixing ratio (initial water vapor mixing ratio minus the equilibrium water vapor mixing ratio at a given level).

${ }^{5}$ The increase in surface water vapor mixing ratio as the LCL decreases also contributes to larger RCIN values in the base states with lower LCLs (owing to more water mass that can be condensed into hydrometeors), but this is of secondary importance in this set of base states.
}

Weisman and Klemp 1984). This strong dynamic lifting has the potential to overcome the CIN in our base states without providing any information about whether the buoyant energy barrier faced by these parcels was closer to the PCIN or RCIN. Another solution to this problem would be to simply add more CIN to the base state, but this can impede storm initiation. Thus, the simplest approach is to remove any vertical wind shear. To test whether weak to moderate amounts of vertical wind shear change our results by causing hydrometeors to fall away from the updraft core, two sets of simulations were also performed using a base state with wind in the $x$ direction that varies linearly with height in the $0-6-\mathrm{km}$ layer with $0-6-\mathrm{km}$ bulk wind differences of 7.5 and $15 \mathrm{~m} \mathrm{~s}^{-1}$. These experiments are denoted S7.5 and S15.

\section{c. Initiation methods}

Several different methods of initiating convection are used in this study. The reason for this is twofold. The first is to show that our results are robust regardless of the initiating method even though these methods may have a large impact on the characteristics of the initial convective cell (Figs. 4 and 5, and, e.g., Morrison et al. 2015), which is what is examined here. The second is that using multiple initiation methods demonstrates how the results presented herein may change as the strength of the updraft forcing changes (i.e., the impact of RCIN on the inflow layer may diminish in the presence of stronger updraft forcing mechanisms, such as what might be expected in a mature supercell). Three types of initiating methods are used: 1) low-level convergence (LLC; Loftus et al. 2008), 2) updraft nudging (U; Naylor and Gilmore 2012), and 3) warm bubble (B; Klemp and Wilhelmson 1978). For each method, different parameters related to the strength of the forcing are used (Table 3). For example, two different maximum convergence values are used within the LLC initiation method to explore how the impact of RCIN on the inflow layer changes when the convergence initiating convection is stronger. Additional sensitivity tests (e.g., tests with 100-m grid spacing) use the LLC2 initiation method and are summarized in Table 4.

\section{d. Passive tracer and parcel analyses}

Similar to Nowotarski et al. (2020), passive tracers (PT) are used to determine the origins of air participating in the updrafts of the simulated storms. PTs are introduced in consecutive 100-m layers from the surface to $4 \mathrm{~km} \mathrm{AGL}$ and then in consecutive 500-m layers from $4 \mathrm{~km}$ AGL to the model top. This results in a total of 72 different PT layers (68 for the 100-m simulations). The PT concentrations within each layer are initially $0.1 \mathrm{~kg} \mathrm{~kg}^{-1}$ when the model is initialized, and as the model is integrated forward in time, the PTs are advected by the governing equations (diffusion also acts on the PT concentrations).

The midlevel updraft is defined as all grid points $5.988 \mathrm{~km}$ AGL with vertical velocity $(w) \geq 3 \mathrm{~m} \mathrm{~s}^{-1}$ and cloud water mixing ratios $\left(q_{c}\right) \geq 0.05 \mathrm{~g} \mathrm{~kg}^{-1}$. The $q_{c}$ threshold helps differentiate between the convective updraft and gravity waves radiating away from the convective cell (ring-like relative maxima in $w$ centered on the main updraft in Figs. 4b,c). The choice for defining the midlevel updraft at 

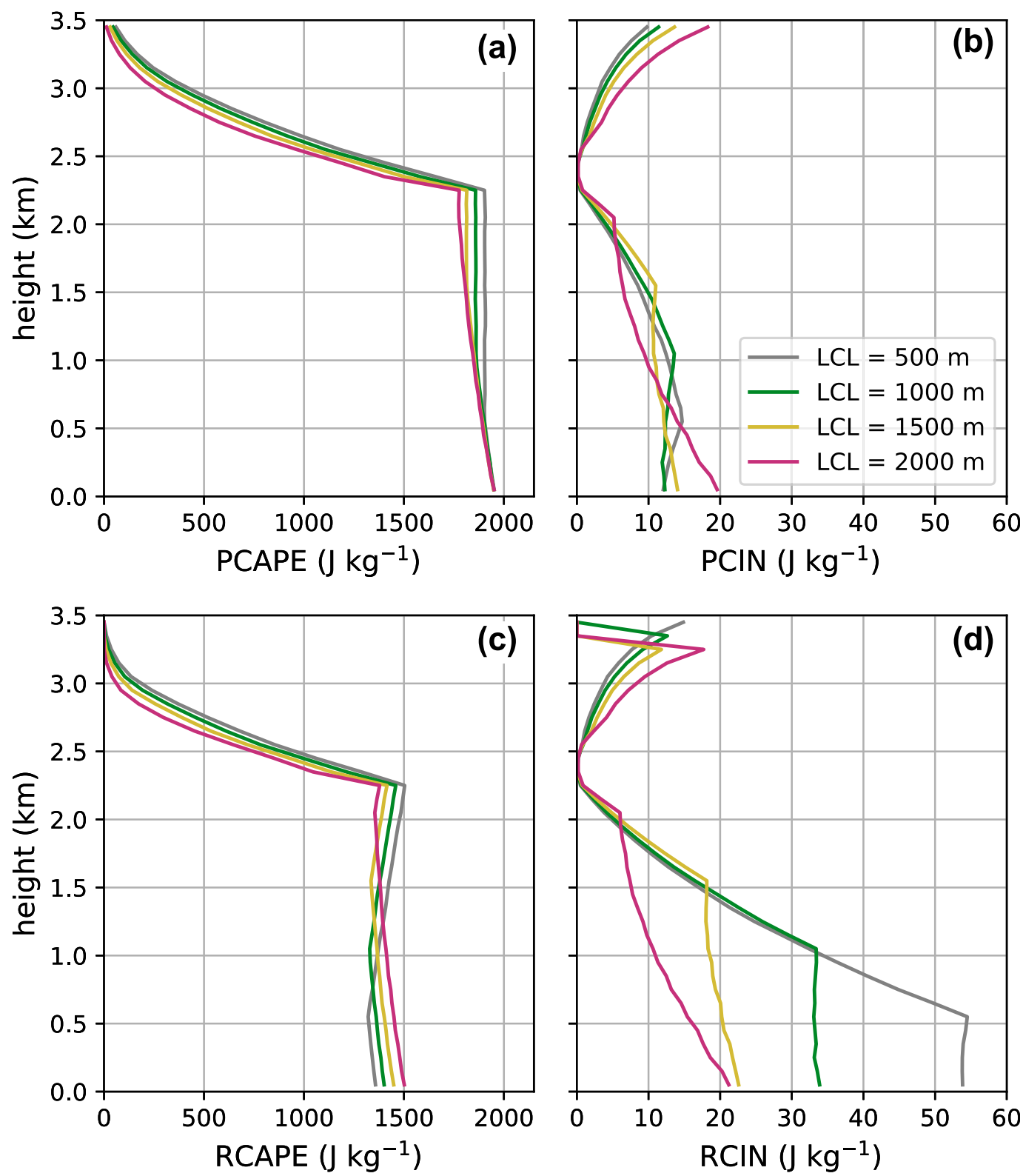

FIG. 3. Thermodynamic parameters for the soundings in Fig. 2 using parcels lifted from the height indicated on the $y$ axis. (a) PCAPE, (b) PCIN, (c) RCAPE, and (d) RCIN, with the different colored lines corresponding to different initial base states. Thermodynamic parameters are computed using the getcape subroutine in CM1.

$5.988 \mathrm{~km}$ is arbitrary, but tests using different altitudes for the midlevel updraft $(5.001,6.963$, and $8.101 \mathrm{~km} \mathrm{AGL)}$ yielded results qualitatively similar to those presented below. Updraft definitions that only consider the largest contiguous area at $5.988 \mathrm{~km}$ AGL with $w \geq 3 \mathrm{~m} \mathrm{~s}^{-1}$ and $q_{c} \geq 0.05 \mathrm{~g} \mathrm{~kg}^{-1}$ were also considered, but were not used owing to the fractured and thermal-like appearance of updrafts in some of the simulations using weaker initiation methods, which resulted in some parts of the midlevel updraft being left out when using this updraft definition. Passive tracer analyses that define the midlevel updraft using the largest contiguous area at $5.988 \mathrm{~km}$ AGL where $w \geq 3 \mathrm{~m} \mathrm{~s}^{-1}$ and $q_{c} \geq 0.05 \mathrm{~g} \mathrm{~kg}^{-1}$ yield the same qualitative results as the PT analyses presented in section 4 (not shown).

We compute the mass of PT $(M)$ from a given level that is fluxed through the updraft from $t_{\text {start }}$ to $t_{\text {end }}$ using the following formula:

$$
M=\sum_{t=t_{\text {start }}}^{t_{\text {end }}} \sum_{n=1}^{N} w_{n, t} \rho_{n, t} q_{\mathrm{pt}, n, t} \Delta x \Delta y \Delta t,
$$

where $\rho_{n, t}$ is the air density, $q_{\mathrm{pt}, n, t}$ is the PT mixing ratio, $\Delta x$ and $\Delta y$ are the gridcell dimensions, and $\Delta t$ is the time interval 
a) LLC

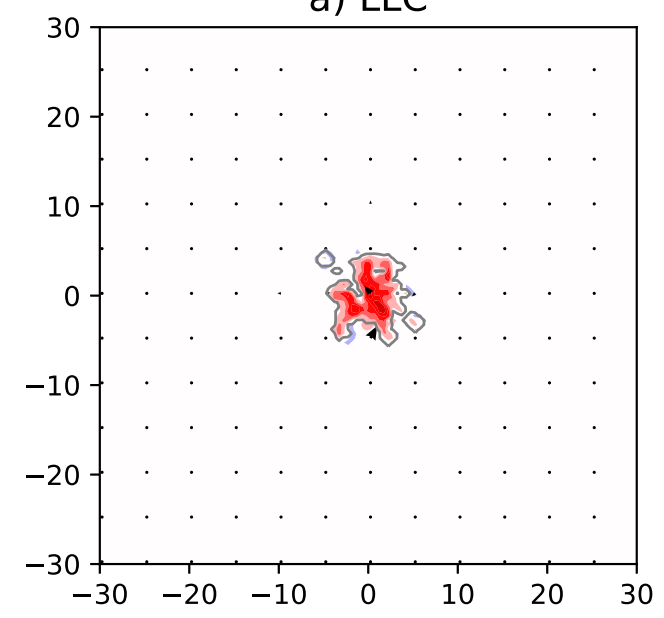

c) U10

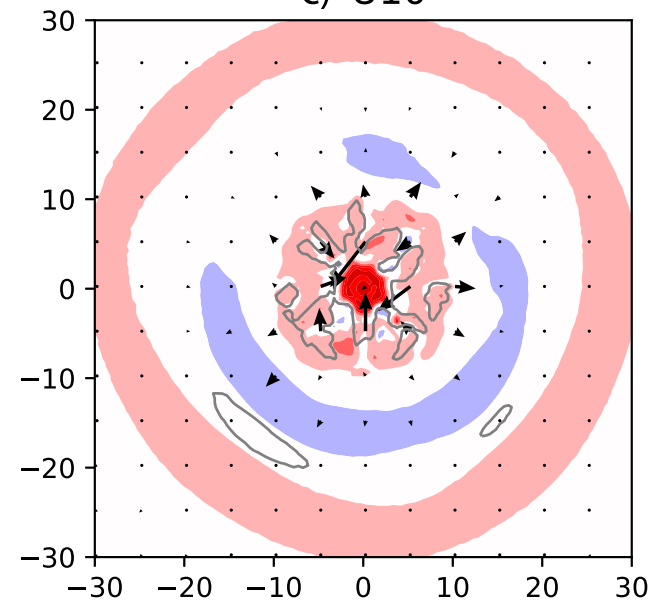

b) LLC2

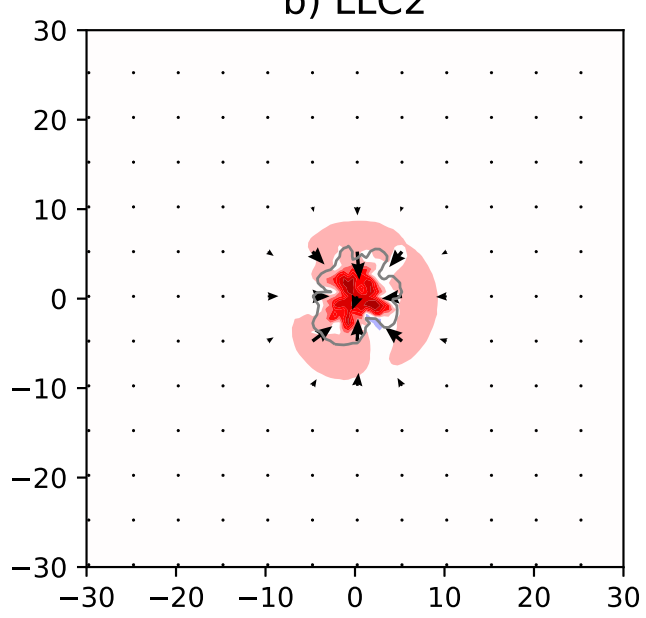

d) S15

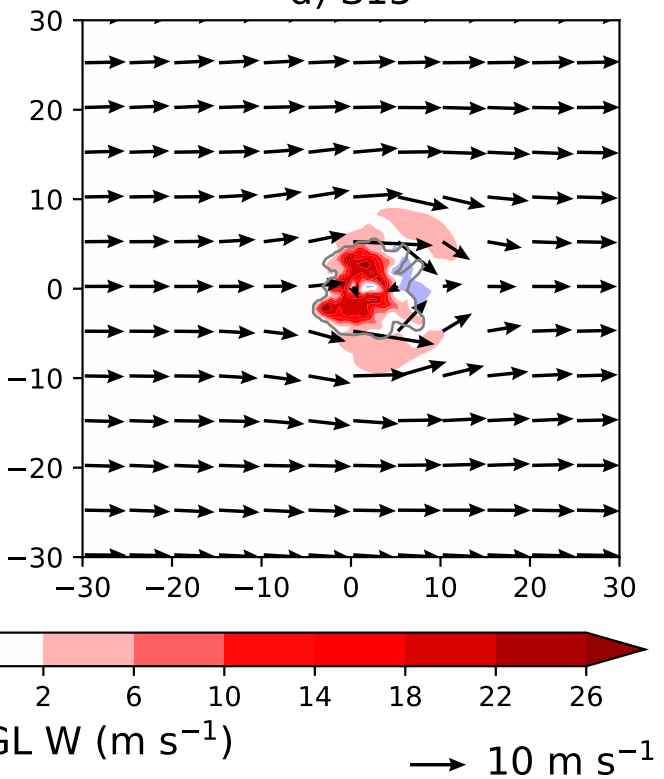

FIG. 4. Horizontal cross sections of select simulations using the LCL $=500-\mathrm{m}$ base state at $t=1800 \mathrm{~s}$. Color shading denotes the 5.988-km vertical velocity field, black arrows denote the horizontal winds at $5.988 \mathrm{~km}$ AGL, and the gray contour denotes the $q_{c}=0.05 \mathrm{~g} \mathrm{~kg}^{-1}$ contour. All axes labels are in $\mathrm{km}$ and each panel is labeled with the experiment abbreviation.

between output files (300s). The first summation is over all output times between $t_{\text {start }}$ and $t_{\text {end }}$ and the second summation is over all $N$ grid points within the midlevel updraft. Thus, $M$ provides an approximation of the total amount of PT mass lifted by the updraft at $5.988 \mathrm{~km}$ AGL during a particular time window.

Parcels are used to explore whether parcel ascent in the lower depths of the simulated storms best resembles pseudoadiabatic or reversible parcel ascent. To do this, parcels are initialized at $t=0 \mathrm{~s}$ in a $20 \mathrm{~km} \times 20 \mathrm{~km}$ grid at $z=250,750$, 1250,1750 , and $2250 \mathrm{~m}$ AGL. A total of 1600 parcels are initialized at each vertical level, resulting in a total of 8000 parcels. These parcels are integrated forward in time for the entire model integration period. For each simulation, updraft parcels are identified by finding those parcels that are above $3 \mathrm{~km}$ AGL and have a vertical velocity greater than $2 \mathrm{~m} \mathrm{~s}^{-1}$ at $t=1800 \mathrm{~s}$. This allows for the examination of only those parcels that participate in the updraft. Tests using updraft parcel criteria with the same $z$ and $w$ thresholds, but applied at $t=1200$ and $2400 \mathrm{~s}$ are qualitatively similar to the results presented in section 3 (not shown), indicating that our results are not sensitive to the analysis time choice.

\section{Parcel analysis}

Vertical profiles of updraft parcel buoyancy and total water mixing ratio $\left(q_{\text {tot }}\right)$ are used to determine if parcel ascent in the 
a) LLC

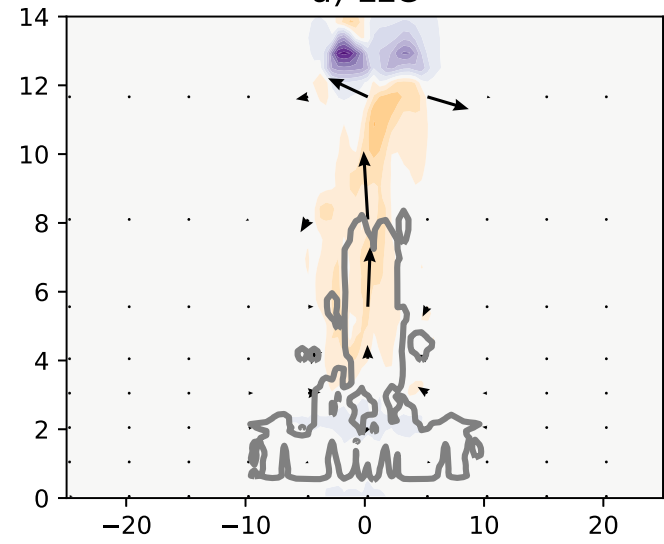

c) U10

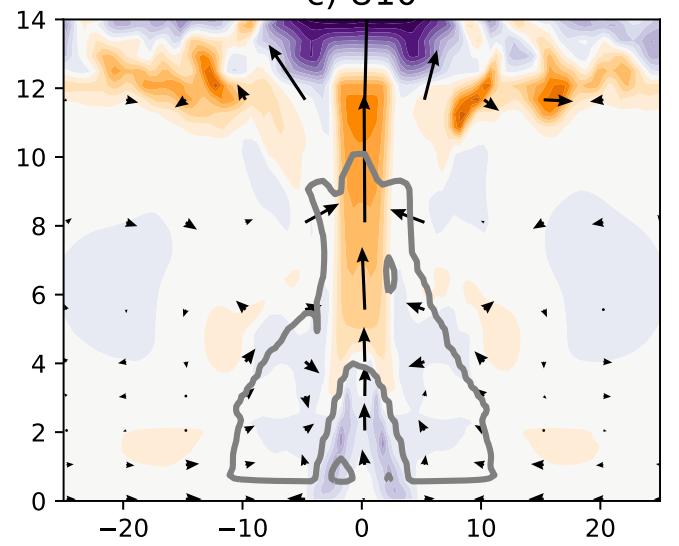

b) LLC2

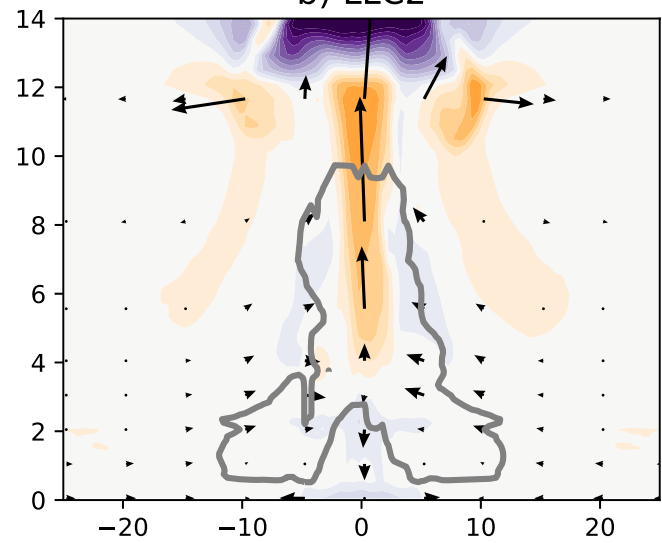

d) S15

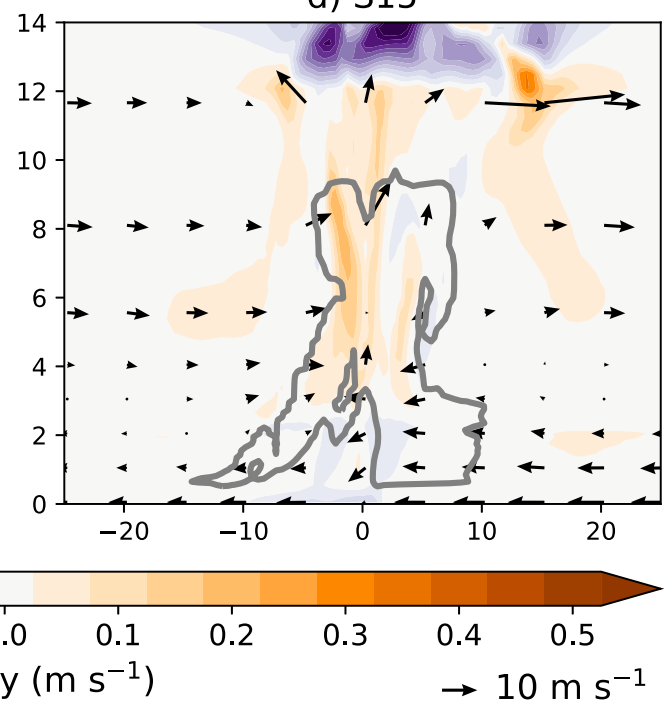

FIG. 5. Vertical cross sections in the $x-z$ plane of select simulations using the LCL $=500-\mathrm{m}$ base state at $t=1800 \mathrm{~s}$ and $y=0.25 \mathrm{~km}$. Color shading denotes buoyancy, black arrows denote the plane-parallel winds, and the gray contour denotes the $q_{c}=0.05 \mathrm{~g} \mathrm{~kg}^{-1}$ contour. All axes labels are in $\mathrm{km}$ and each panel is labeled with the experiment abbreviation.

lowest few kilometers best resembles pseudoadiabatic or reversible parcel ascent. The LCL $=500 \mathrm{~m}$ simulations are examined in detail owing to the large differences between RCIN and PCIN at lower levels in this base state compared to the base states with higher LCLs (Fig. 3). For the LLC2 initiation method, vertical profiles of both buoyancy and $q_{\text {tot }}$ are similar to the vertical profiles of buoyancy and $q_{\text {tot }}$ expected from parcel theory using reversible ascent (as opposed to pseudoadiabatic ascent), especially in the lowest $2.5 \mathrm{~km}$ AGL (Figs. 6 and 7). Surprisingly, $q_{\text {tot }}$ actually increases with height in all updraft parcels initiated at $250 \mathrm{~m}$ AGL and in a subset of the updraft parcels initiated at $750 \mathrm{~m}$ AGL, which contrasts both pseudoadiabatic ( $q_{\text {tot }}$ decreases with height) and reversible ( $q_{\text {tot }}$ is constant with height) parcel ascent (Figs. 7a,b). This is likely the result of precipitation falling into these updraft parcels from above. This additional hydrometeor loading results in buoyancies that are more negative than would be expected from parcel theory (e.g., Fig. 6a near $z=1500 \mathrm{~m}$ ). Interestingly, this spike in negative buoyancy near $z=1500 \mathrm{~m}$ is also seen in the simulations with vertical wind shear (not shown). One hypothesis for this observation is that the hydrometeors that contribute to this spike in negative buoyancy originated within a few kilometers above $z=1500 \mathrm{~m}$ and, therefore, do not have time to be advected far from the updraft by the background wind in the simulations with vertical wind shear before reaching $z=1500 \mathrm{~m}$. This result, that precipitation from above may reduce parcel buoyancy below that expected from reversible parcel ascent, was also suggested by $\mathrm{Xu}$ and Emanuel (1989) based on their analysis of observed tropical soundings.

In contrast to the $\mathrm{LCL}=500-\mathrm{m}$ base state, pseudoadiabatic and reversible parcel ascent are indistinguishable in the lowest 
TABLE 3. Convective initiation methods used in the CM1 experiments. Parameters for each initiating method use the default values in CM1, release 19.8, except where noted in the last column.

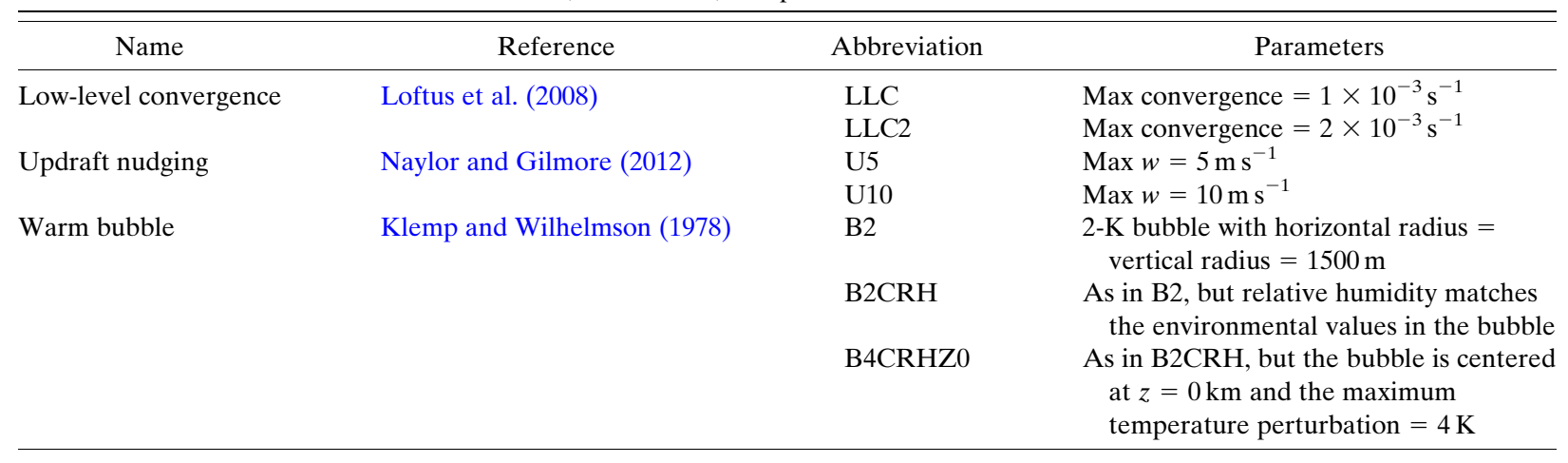

$2500 \mathrm{~m}$ of the $\mathrm{LCL}=2000$-m base state (Fig. 8 ). This highlights how the difference between a pseudoadiabat and reversible moist adiabat in the lowest few kilometers depends on the distance between the LCL and LFC. If the LFC is near cloud base, as is the case in the LCL $=2000-\mathrm{m}$ base state, the choice of PCIN or RCIN does not matter. If the LFC is above cloud base, the choice of PCIN or RCIN does matter, as is the case in the $\mathrm{LCL}=500-\mathrm{m}$ base state. Once within the cloud, the pseudoadiabat and reversible moist adiabat diverge in the $\mathrm{LCL}=2000$ - $\mathrm{m}$ base state, which explains why the $\mathrm{LCL}=2000$ $\mathrm{m}$ base state has different PCAPE and RCAPE values.

To generalize the result that parcel ascent in the lower troposphere is best represented by reversible instead of pseudoadiabatic parcel ascent, we compute root-meansquare differences (RMSD) between parcel buoyancy from CM1 and parcel buoyancy predicted by parcel theory (using either pseudoadiabatic or reversible parcel ascent). RMSDs are computed over the lowest $2500 \mathrm{~m}$ AGL and first $1800 \mathrm{~s}$ of the simulation using parcel properties output every $300 \mathrm{~s}$. RMSDs are only computed for updraft parcels originating at 250, 750, 1250 , and $1750 \mathrm{~m}$ AGL for simulations using the $\mathrm{LCL}=500-\mathrm{m}$ base state, excluding those simulations initiated using warm bubbles. Simulations using a warm bubble for convection initiation are not examined here because the presence of the warm bubble alters the buoyancy field, which makes comparisons to parcel theory difficult. For all nine simulations and all four updraft parcel origin heights examined, RMSDs of buoyancy are smaller when reversible parcel ascent is used instead of pseudoadiabatic parcel ascent (Fig. 9). RMSDs for $q_{\text {tot }}$ are computed in a similar fashion and are also smaller for reversible parcel ascent compared to pseudoadiabatic parcel ascent (Fig. 10). These results bolster the claim that parcel ascent in the lowest few kilometers best resembles reversible instead of pseudoadiabatic parcel ascent, and that this result is qualitatively insensitive to the initiation method, microphysics parameterization, presence of weak to moderate vertical wind shear, and grid spacing. It is noteworthy that neither increasing the autoconversion nor adding vertical wind shear has a large impact on these RMSDs other than a slight increase in the reversible RMSDs compared to LLC2. Although both more aggressive autoconversion and environmental vertical wind shear appear to slightly push low-level parcel ascent toward the pseudoadiabatic extreme, RMSDs for reversible parcel ascent are still much lower compared to pseudoadiabatic parcel ascent (e.g., Fig. 9b), indicating that parcel ascent is still best conceptualized as a reversible moist adiabatic process.

It should be noted that hydrometeor loading is not the only mechanism that can cause parcel buoyancies to be less than those predicted by parcel theory using pseudoadiabatic ascent. Mixing between a parcel and its environment owing to entrainment as it rises can also decrease parcel buoyancy and can be a major factor in preventing a parcel from reaching the maximum vertical velocity predicted by parcel theory (e.g., Wei et al. 1998). However, $\theta_{e p}$ is constant in the lowest $2300 \mathrm{~m}$ in each of the base states, so entrainment would be expected to only have a small impact on parcel buoyancy, unlike farther aloft where parcels would be mixing with environmental air that is much cooler and drier. To further highlight that hydrometeor loading and not entrainment is responsible for the decrease in parcel buoyancy relative to that predicted from theory using pseudoadiabatic ascent, buoyancies for the updraft parcels in the LCL $=500 \mathrm{~m}$, LLC2 experiment are recomputed without the effects of hydrometeor loading (Fig. 11). The resulting buoyancies in the lowest $\sim 2500 \mathrm{~m}$ closely follow those predicted by theory using pseudoadiabatic parcel ascent. Therefore, the departures in parcel buoyancy from those predicted by parcel theory using pseudoadiabatic ascent in Fig. 6 are likely

TABLE 4. Additional experiments using the LLC2 initiation method.

\begin{tabular}{|c|c|}
\hline Abbreviation & Description \\
\hline NSSL & NSSL microphysics scheme \\
\hline AUT & $\begin{array}{l}\text { Morrison microphysics scheme with } \\
\text { autoconversion from cloud water to rain } \\
\text { increased by a factor of } 10\end{array}$ \\
\hline S7.5 & $\begin{array}{l}\text { Constant vertical wind shear in the } x \text { direction } \\
\text { with } 0-6-\mathrm{km} \text { bulk wind difference }=7.5 \mathrm{~m} \mathrm{~s}^{-1}\end{array}$ \\
\hline S15 & $\begin{array}{l}\text { Constant vertical wind shear in the } x \text { direction } \\
\text { with } 0-6-\mathrm{km} \text { bulk wind difference }=15 \mathrm{~m} \mathrm{~s}^{-1}\end{array}$ \\
\hline 100 & $\begin{array}{l}\text { 100-m horizontal grid spacing and an initial large } \\
\text { time step of } 1 \mathrm{~s}\end{array}$ \\
\hline
\end{tabular}




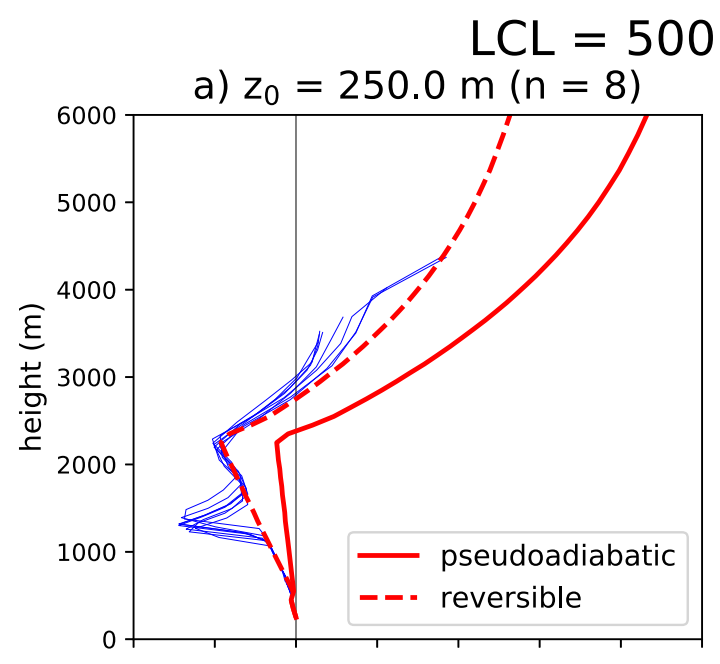

$\mathrm{m}, \mathrm{LLC2}$

b) $z_{0}=750.0 \mathrm{~m}(\mathrm{n}=508)$
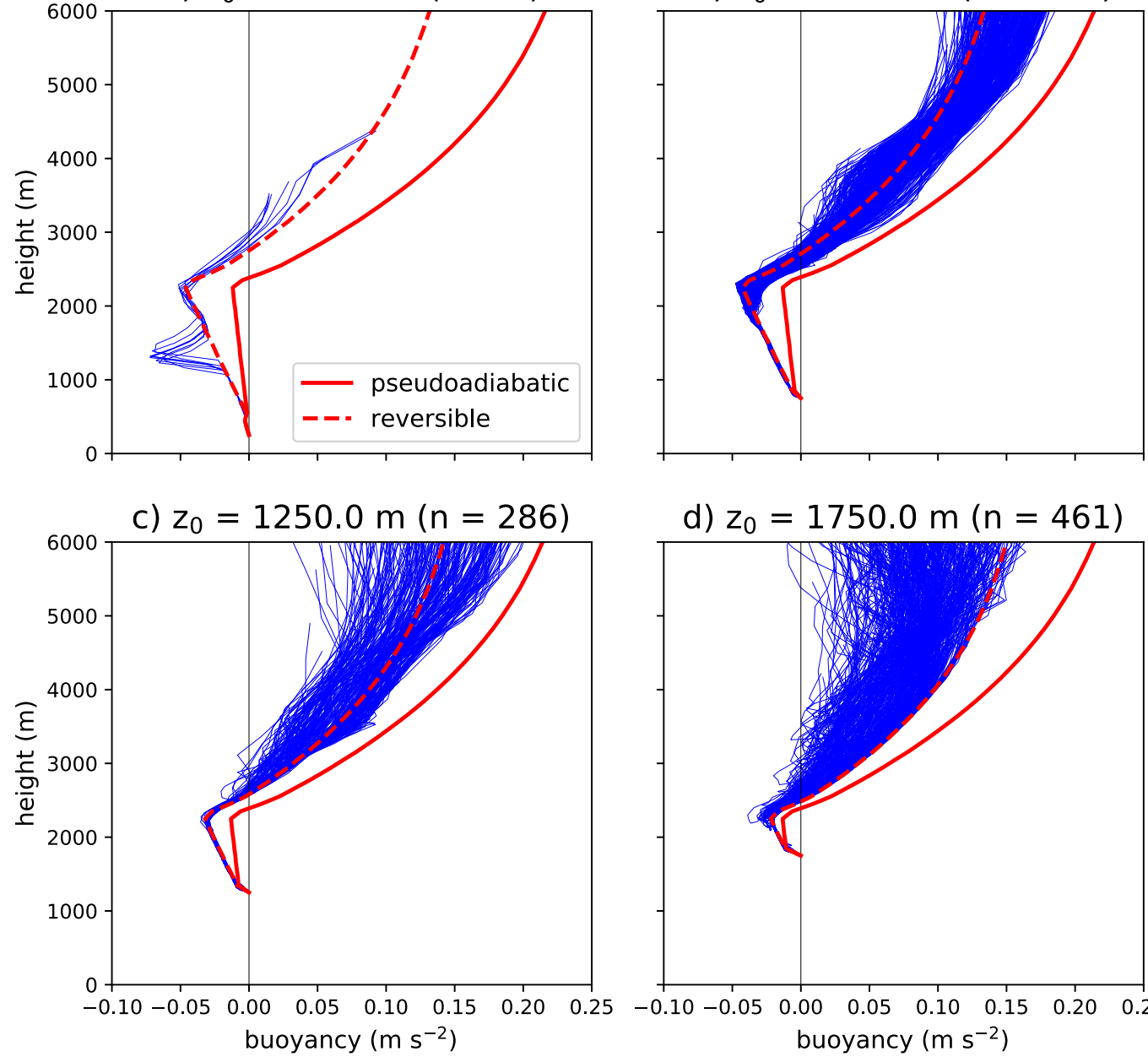

d) $z_{0}=1750.0 m(n=461)$

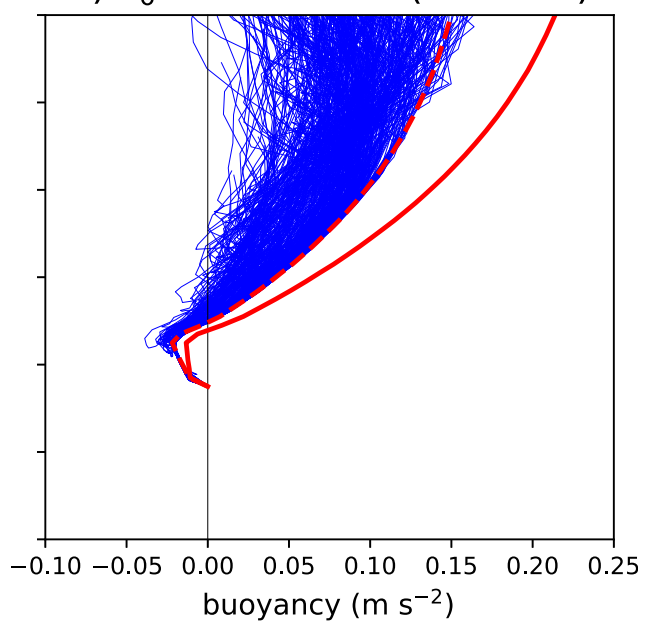

FIG. 6. Vertical profiles of parcel buoyancy for updraft parcels in the simulation using the LCL $=500-\mathrm{m}$ base state and the LLC2 initiation method (blue lines). Updraft parcels originating at $z_{0}=$ (a) 250, (b) 750, (c) 1250, and (d) $1750 \mathrm{~m}$ are individually plotted with blues lines, and the number of parcels plotted in each panel is listed in the respective subtitle [e.g., $n=8$ parcels are plotted in (a)]. The solid and dashed red lines are the buoyancy profiles expected from parcel theory using pseudoadiabatic and reversible moist adiabatic parcel ascent, respectively.

primarily the result of hydrometeor loading, with entrainment playing a lesser role.

\section{Passive tracer analysis}

The source of air contributing to the midlevel updraft is probed using $M$ values at $5.988 \mathrm{~km}$ AGL computed over the 0-2700-s time window. To allow for an easier comparison between the different base states and initiation methods used, $M$ values are normalized by the sum of the $M$ values from all 72 PTs within a given simulation (Fig. 12). The $0-2700$-s time window is selected for computing $M$ because all simulations had midlevel updrafts meeting the criteria outlined in section $2 \mathrm{~d}$ at the end of this window and secondary convection is not widespread yet. Other time windows were examined (e.g., 0-3600, 1200-1800s), and the results from those other time windows are qualitatively similar to the results presented below.

The one commonality between all the simulations is that the largest normalized $M$ values occur somewhere in the lowest $2 \mathrm{~km} \mathrm{AGL}$, over a kilometer below the top of the layer with $\mathrm{PCAPE} \geq 100 \mathrm{~J} \mathrm{~kg}^{-1}$ (Fig. 12), which would be the top of the EIL using the definition of Thompson et al. (2007). Interestingly, there is no noticeable decrease in normalized $M$ values as PCAPE values drop to zero in the $3-4-\mathrm{km}$ layer, which means that parcels with little to no PCAPE originating near the top and above the EIL are both reaching the midlevel updraft in similar quantities. As discussed in Nowotarski et al. (2020), the presence of nonbuoyant air from above the EIL in the midlevel updraft may be the result of the entrainment of this air into the updraft. Because these are simulations of ordinary convection, large amounts of midlevel 


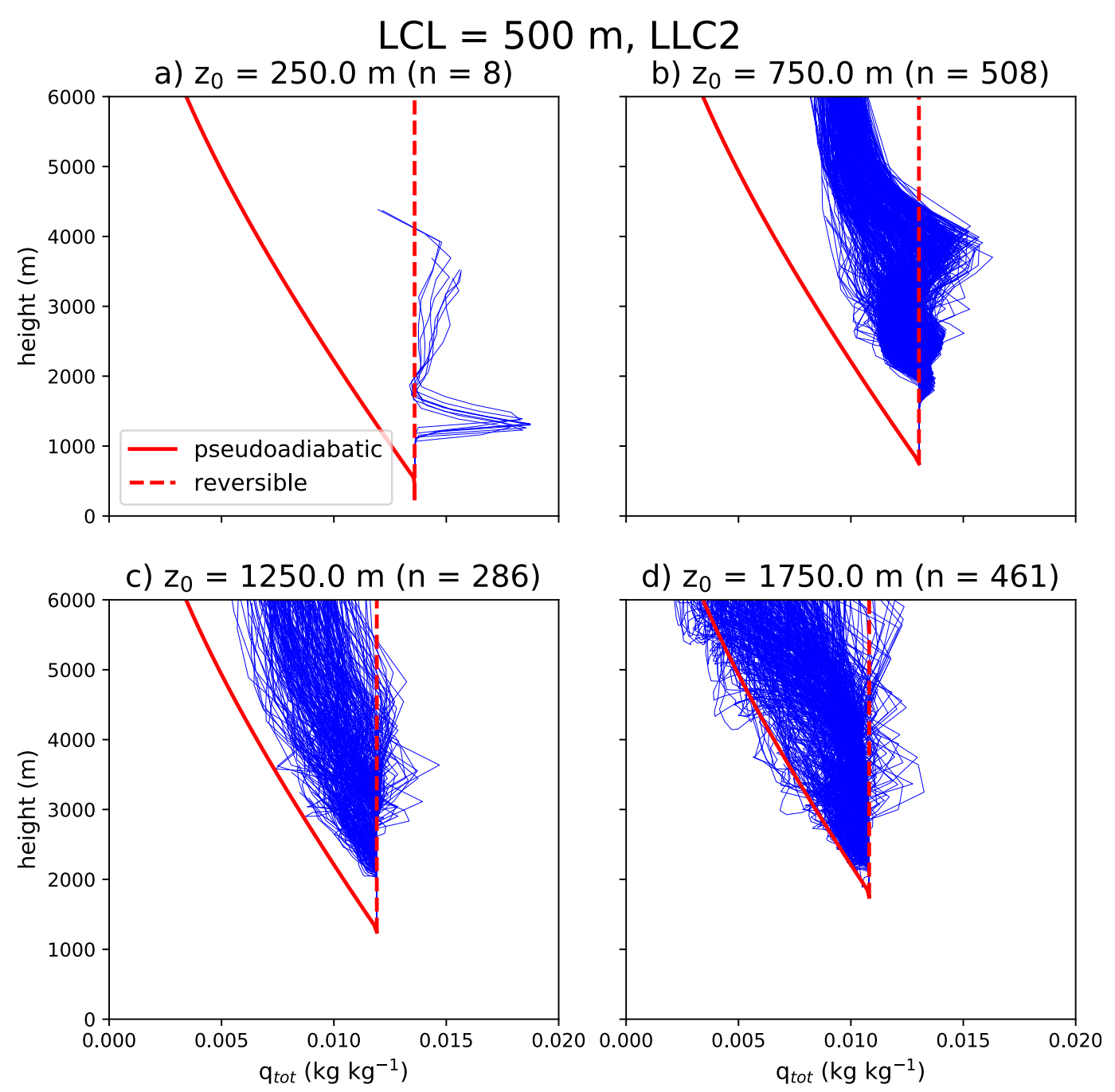

FIG. 7. As in Fig. 6, but for total water mixing ratio $\left(q_{\text {tot }}\right)$ instead of buoyancy.

entrainment would be expected owing to the relatively narrow updraft cores [compared to, e.g., supercells (Peters et al. 2020)]. For the rest of this discussion, the inflow layer will be defined as those levels with normalized $M>0.0175$ because this is one of the lowest thresholds that can be used that exclude the parcels above the EIL that possess no positive buoyancy (Fig. 12).

The location of the inflow layer exhibits dependencies on both the initial base state and initiation method. For a majority of the initiation methods (all except U10 and B4CRHZ0), all three microphysics parameterizations, and both vertical shear values, the inflow layer base drops in altitude as the base state LCL is raised and the RCIN of parcels in the lowest $500 \mathrm{~m}$ AGL is reduced (Fig. 12). The simulations using the U10 initiation method, on the other hand, all have inflow layers that stretch down to the surface, no matter the base state. In fact, the U10 simulations exhibit little variation in the vertical normalized $M$ profiles as the base state is changed, especially between the LCL $=500-, 1000-$, and $1500-\mathrm{m}$ base states (Fig. 12d). The simulations using the B4CRHZ0 initiation method depart significantly from the other initiation methods, with the inflow layer spanning from the surface to only $\sim 1 \mathrm{~km}$ AGL (Fig. $12 \mathrm{~g}$ ). These simulations also exhibit minimal variation in the vertical profiles of normalized $M$ between the LCL $=500-, 1000-$, and $1500-\mathrm{m}$ base states.

The observations made above can be partially explained using the vertical profiles of CAPE and CIN presented in Fig. 3. The EIL from Thompson et al. (2007) relies on the idea that only those parcels with appreciable CAPE and minimal CIN will contribute to the inflow layer. An examination of the vertical profiles of PCAPE and RCAPE shows that the largest CAPE values are concentrated in the lowest $2.3 \mathrm{~km}$ AGL in each of the base states with CAPE decreasing rapidly above the 2.3-km level (Figs. 3a,c). Not surprisingly, the top of the inflow layer for a majority of the simulations lies near the 2.3-km level (the largest exceptions being the B4CRHZ0 simulations). The observed differences in the bottom of the inflow layer as the base state is changed in a majority of the 


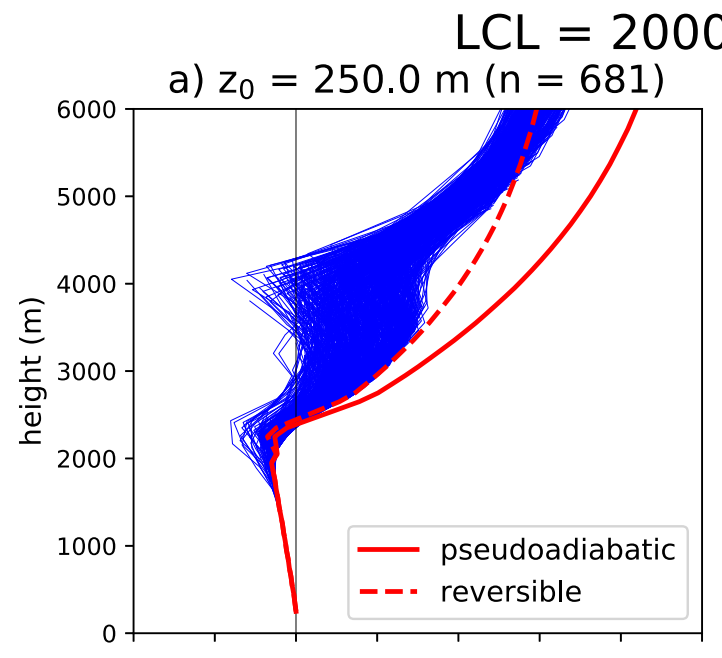

$\mathrm{m}, \mathrm{LLC2}$

b) $z_{0}=750.0 \mathrm{~m}(\mathrm{n}=511)$
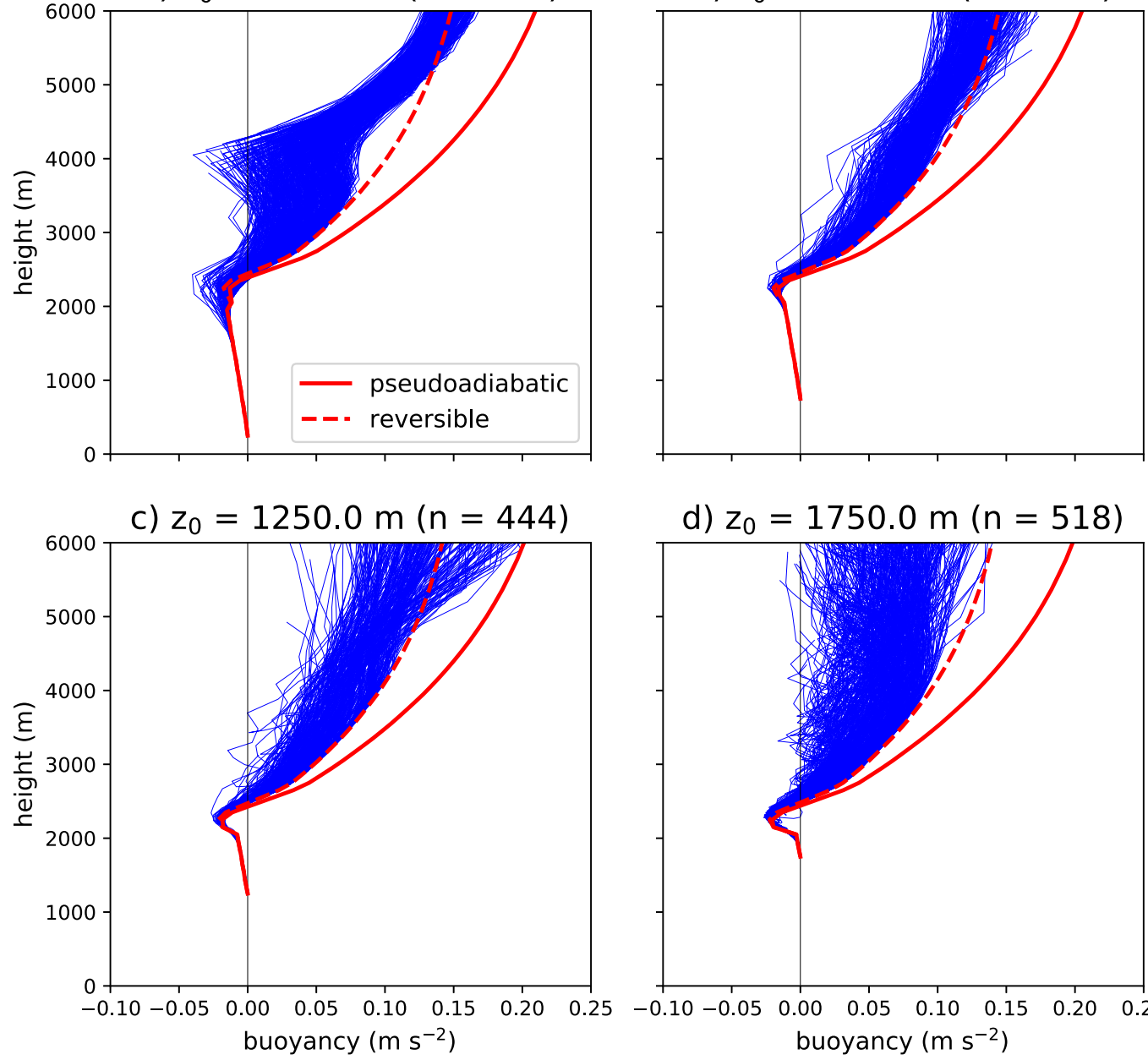

d) $z_{0}=1750.0 \mathrm{~m}(\mathrm{n}=518)$

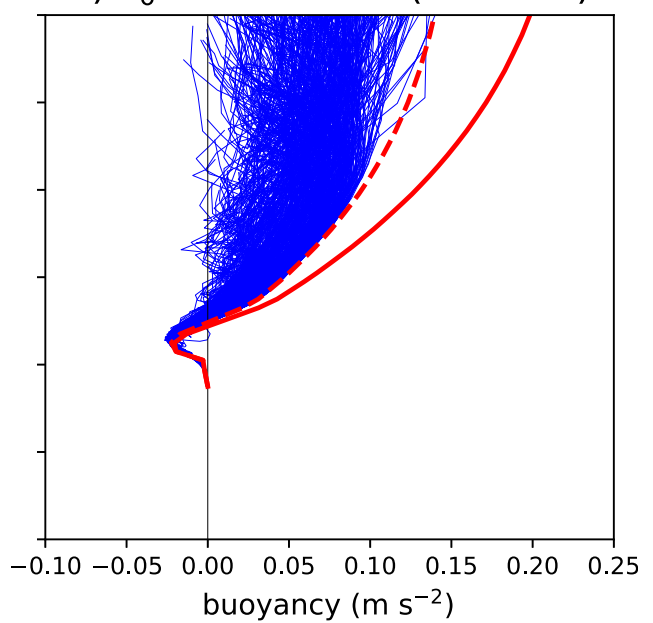

FIG. 8. As in Fig. 6, but for the LCL = 2000-m LLC2 simulation.

experiments can be explained using the vertical profiles of RCIN. It appears that as the RCIN of a layer increases, simulated storm updrafts are less likely to lift parcels from that layer, despite the fact that the PCIN is relatively unchanged (Figs. 3b,d and 12). Therefore, it appears that only those parcels with substantial CAPE and minimal RCIN (not PCIN) drive the convective updraft, which agrees with the conceptual basis of the EIL.

To further show that RCIN and not PCIN is the relevant quantity when determining the inflow layer, all simulations in Fig. 12 are repeated with hydrometeor loading ignored in the vertical momentum equation. ${ }^{6}$ Without hydrometeor loading, the location of the bottom of the inflow layers for all the simulations lies either at the surface or within the lowest few hundred $\mathrm{m} \mathrm{AGL}$, and there is little variation in the bottom of

\footnotetext{
${ }^{6}$ Unlike the calculations in Fig. 11, the impact of hydrometeor loading on buoyancy in these simulations is ignored during the forward time integration in CM1.
}

the inflow layer as the base state is changed (Fig. 13). This is likely because the energy barrier facing parcels in these simulations is now more similar to the PCIN instead of the RCIN, and PCIN for these parcels is relatively small and exhibits little variation between the different base states (Figs. 3b,d). The results of these simulations without hydrometeor loading suggest that differences in the amount of air ingested from the lowest $500 \mathrm{~m}$ AGL in most of the simulations (other than U10 and B4CRHZ0) can largely be attributed to the effects of hydrometeor loading, which is accounted for when computing RCIN.

Sensitivity tests using the LLC2 initiation method with the $100-\mathrm{m}$ grid spacing configuration agree with the results presented above. As the LCL increases, the bottom of the inflow layer decreases, and if hydrometeor loading is neglected, significantly more parcels can be ingested from the lowest levels when using the LCL $=500-\mathrm{m}$ base state (Fig. 14). Thus, the result that RCIN, not PCIN, should be used when determining the inflow layer does not change if the horizontal grid spacing is reduced. 
a) $z_{0}=250.0 \mathrm{~m}$
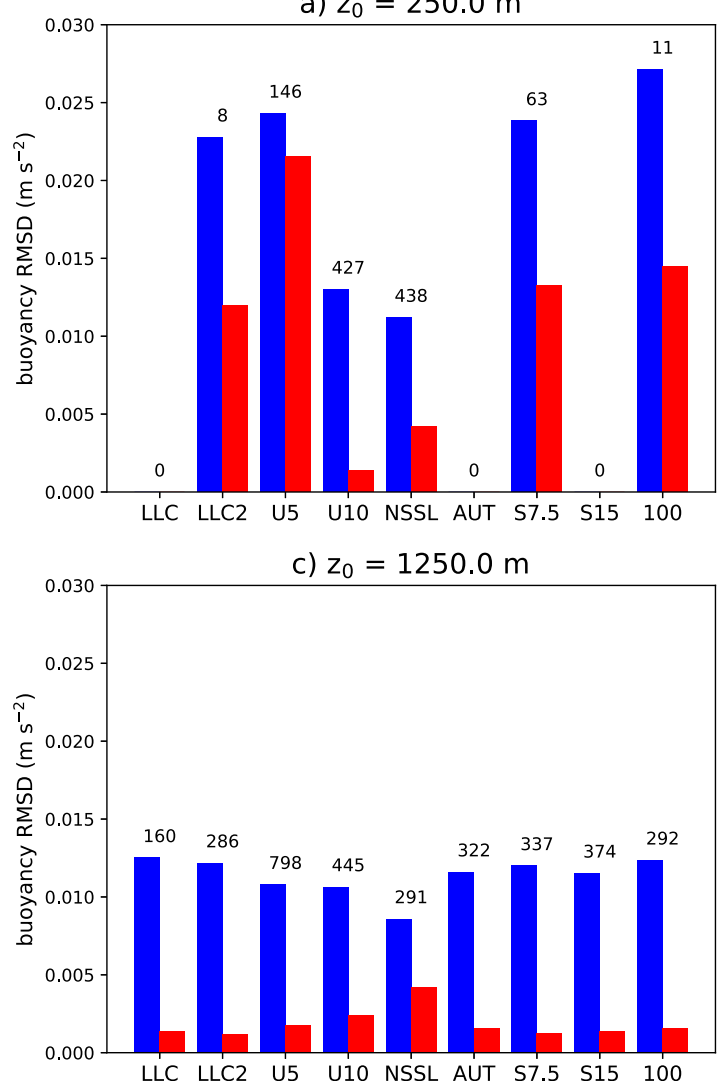

b) $z_{0}=750.0 \mathrm{~m}$

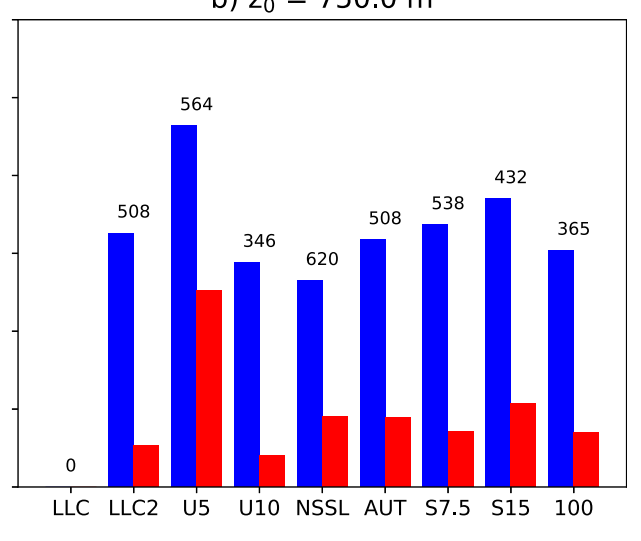

d) $z_{0}=1750.0 \mathrm{~m}$

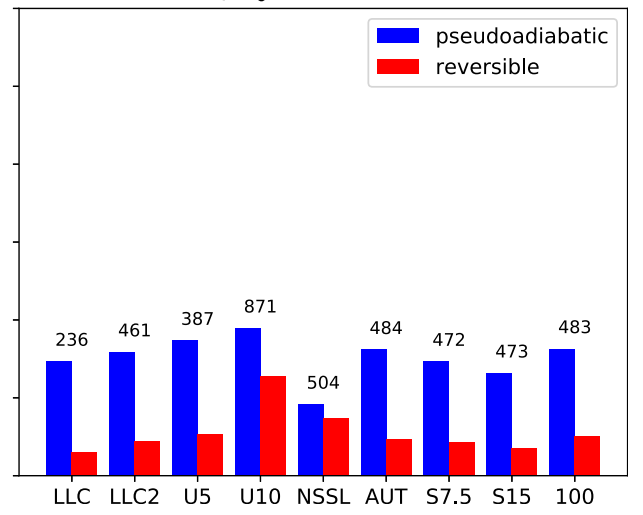

FIG. 9. Root-mean-square differences between parcel buoyancies computed by CM1 and those predicted by parcel theory for updraft parcels in simulations using the LCL $=500-\mathrm{m}$ base state. Buoyancies predicted by parcel theory are computed using pseudoadiabatic (blue bars) and reversible (red bars) parcel ascent. The abbreviations for each experiment on the $x$ axis are defined in Tables 3 and 4. The number of updraft parcels in each pair of bars is listed above the two bars and $z_{0}$ denotes the initial parcel height. RMSDs are computed over the first $1800 \mathrm{~s}$ using output from when the parcels are below $2500 \mathrm{~m}$ AGL.

Two of the experiments (U10 and B4CRHZ0) are able to ingest substantial amounts of air from the lowest $500 \mathrm{~m}$ when using the $\mathrm{LCL}=500-\mathrm{m}$ base state despite the large RCIN possessed by these parcels. We attribute this to the initiation methods used in these simulations. The U10 initiation method is the strongest initiation method used, and it appears that this initiation method provides a strong enough forcing to overcome the RCIN of parcels in the lowest $500 \mathrm{~m}$ AGL and, therefore, ingest large amounts of air from this layer. A comparison between the LLC and LLC2 simulations supports this claim that simulations using stronger initiation methods can ingest more high-RCIN air. For these two initiation methods, the base of the inflow layers are consistently lower for the simulations using the stronger LLC2 initiation method compared to the weaker LLC initiation method (Figs. 12a,b). A similar argument can be made using the U5 and U10 simulations, though it is less clear (Figs. 12c,d). The B4CRHZ0 simulations, on the other hand, ingested large quantities of high-RCIN air from the lowest $1 \mathrm{~km}$ AGL owing to the fact that this initiation method is both relatively strong and centered on the surface (the other warm bubbles are centered at $1500 \mathrm{~m}$ AGL). The large temperature perturbations associated with the B4CRHZ0 initiation method erased the RCIN and increased the CAPE of parcels in the lowest $1 \mathrm{~km}$ (Fig. 15), making it easy for these parcels to be ingested by the storm. Altogether, these observations support the claim that the strength and location of the updraft forcing can modulate the inflow layer and allow storms to ingest air with considerable RCIN.

The impact of the updraft forcing on the inflow layer discussed above suggests that the inflow layer of a storm may actually change as a storm matures and the updraft forcing strengthens. For example, a newly formed cumulonimbus in a strongly sheared environment may only ingest those parcels with appreciable CAPE and little RCIN, but as the storm matures and develops into a supercell with strong low-level dynamic lifting, it may be able to ingest parcels with larger RCIN than it could before owing to the stronger updraft forcing (a similar hypothesis was mentioned in Richardson 1999). Thus, the depth of the inflow layer would increase with time in this case (similar to, e.g., Gray and Frame 2019). 


$$
\mathrm{LCL}=500 \mathrm{~m}
$$

a) $z_{0}=250.0 \mathrm{~m}$
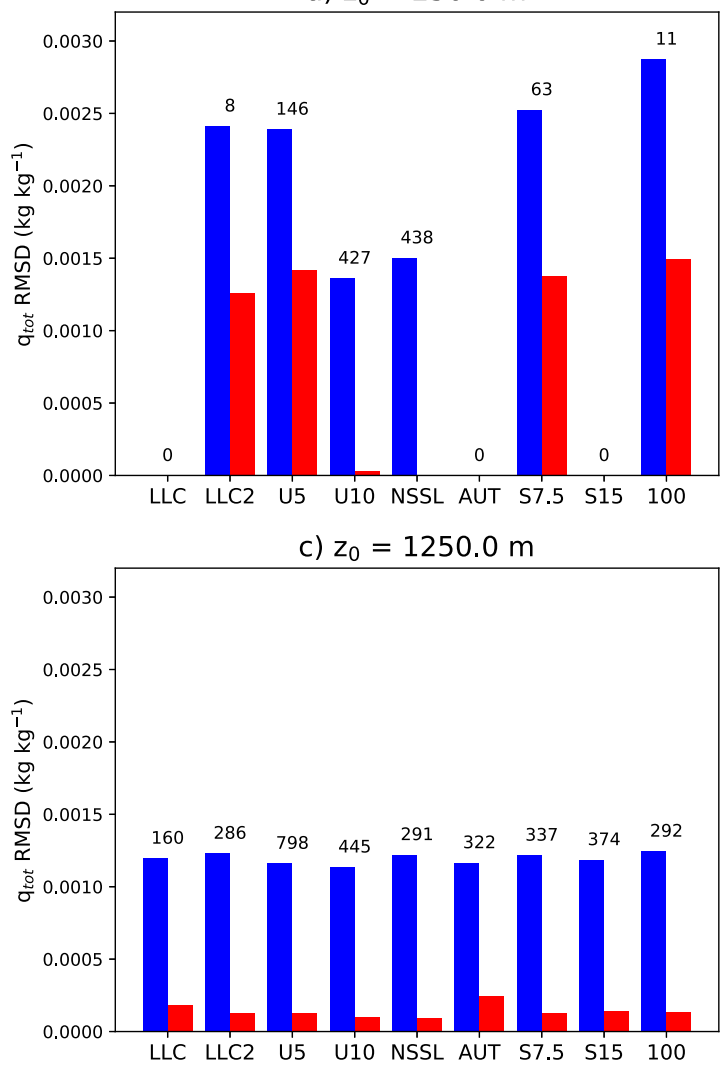

b) $z_{0}=750.0 \mathrm{~m}$
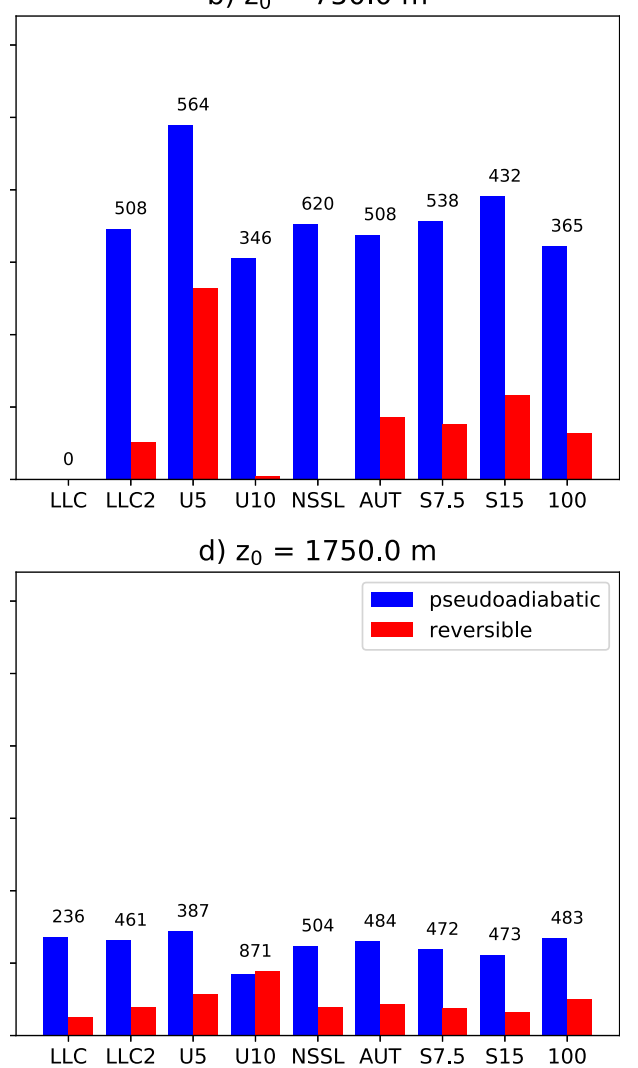

FIG. 10. As in Fig. 9, but for parcel $q_{\text {tot }}$ instead of parcel buoyancy.

The idea that a stronger updraft forcing can overcome large amounts of RCIN and potentially deepen the inflow layer of a storm agrees with results from previous studies that organized forms of convection with strong lifting mechanisms (e.g., supercells and squall lines) can still lift near-surface air parcels even after the CIN of these parcels increases substantially (e.g., Parker 2008; Nowotarski et al. 2011). This also suggests that adding additional metrics to the EIL definition that are related to the low-level dynamic updraft forcing (such as SRH) may improve the skill of the EIL in isolating those parcels that participate in the updraft (a similar idea related to large environmental SRH compensating for large environmental CIN was suggested by Davies 2004). Nowotarski et al. (2020) found that adding a storm-relative wind criterion to the EIL improved the skill of the EIL in determining the inflow layer in some of their simulations when a more stringent updraft definition was used, but overall the skill of the EIL was reduced compared to the original Thompson et al. (2007) definition when all simulations across a range of updraft definitions were considered. Therefore, although the results presented here suggest that updraft forcing is important in determining the inflow layer, it is unclear how this can be incorporated into the EIL definition.

Before closing this section, it is worth noting that the results presented here appear to disagree with McCaul and Cohen
(2002), who hypothesized that "storms effectively ingest ambient environmental air that resides below an altitude of approximately $2 \mathrm{~km}$, regardless of the LCL and LFC heights and the $\theta_{e}$ profile shape below $2 \mathrm{~km}$ "' (p. 1744, McCaul and Cohen 2002). As seen in Fig. 12, changing the LCL within the base state of these simulations of ordinary convection alters the location of the bottom of the inflow layer, causing storms to less "effectively" lift air from near the surface. It is possible that part of this discrepancy is due to the fact that McCaul and Cohen (2002) focused on mature supercells, which have strong low-level vertical perturbation pressure gradient accelerations, whereas the focus herein is on ordinary convection with much weaker updraft forcings. The nearly constant inflow layer depths in the simulations of McCaul and Cohen (2002) may have been anticipated if an additional parameter was added to the EIL that accounted for the dynamic updraft forcings seen in the lowest few kilometers of supercells.

\section{Summary}

This study examines whether reversible CIN or pseudoadiabatic CIN should be used when determining the inflow layer of a convective storm. To this end, idealized CM1 simulations of ordinary convective storms were performed using four different base states that featured varying differences between 


\section{$\mathrm{LCL}=500 \mathrm{~m}, \mathrm{LLC2}$, Ignore Hydrometeor Loading}

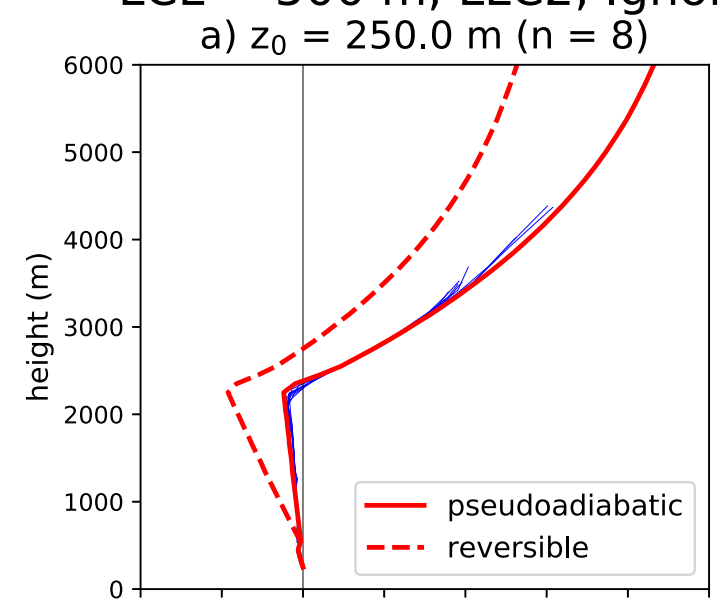

b) $z_{0}=750.0 \mathrm{~m}(\mathrm{n}=508)$
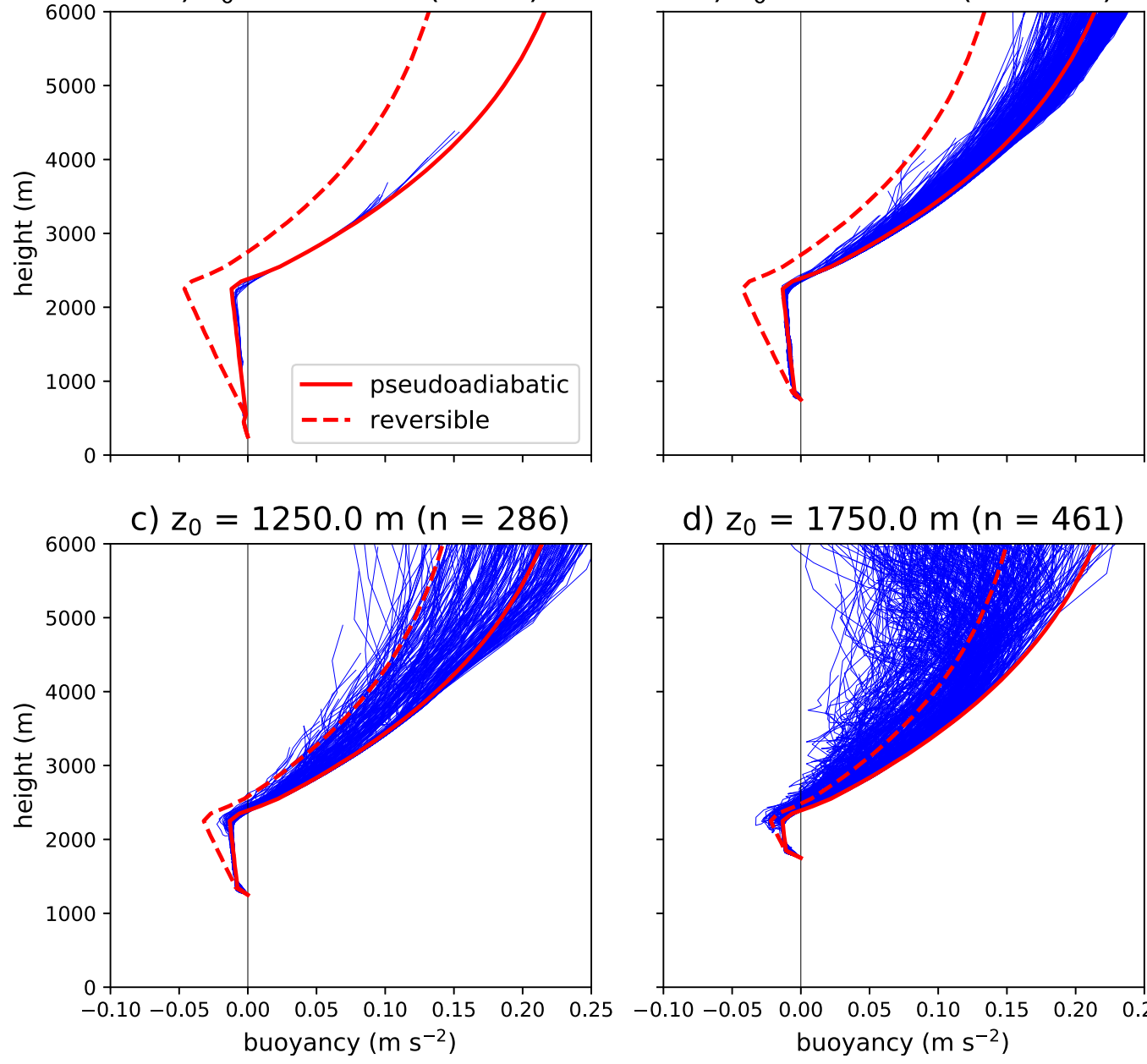

d) $z_{0}=1750.0 \mathrm{~m}(\mathrm{n}=461)$

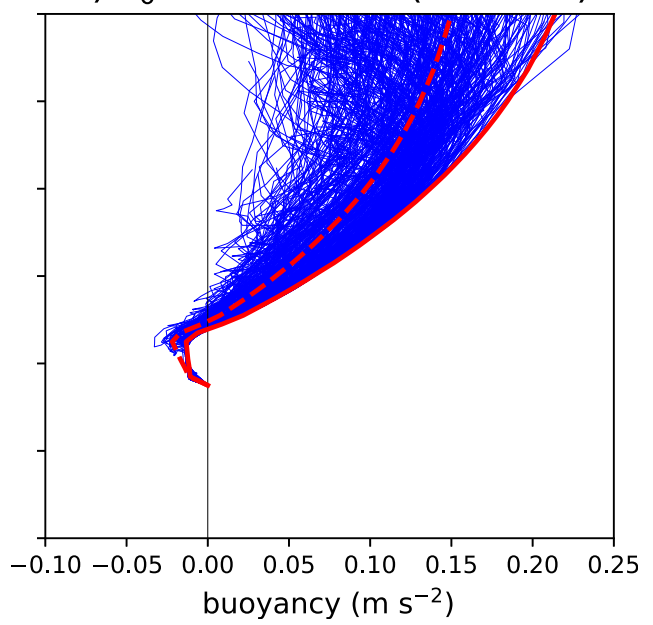

FIG. 11. As in Fig. 6, but hydrometeor loading is ignored when computing parcel buoyancies.

the RCIN and PCIN for parcels originating in the lowest $\sim 500 \mathrm{~m}$ AGL. Both the PCAPE values and the depth of the layer with $\mathrm{PCAPE} \geq 100 \mathrm{~J} \mathrm{~kg}^{-1}$ were comparable between all of the base states. Several different convection initiation methods, three different microphysics schemes, three different base-state vertical wind shear values, and two different horizontal grid spacings were also tested to examine the sensitivity to the initial updraft forcing, microphysics, weak-to-moderate vertical wind shear, and model resolution.

An analysis of updraft parcels suggests that parcel ascent in the lowest $2.5 \mathrm{~km}$ AGL best resembles reversible as opposed to pseudoadiabatic parcel ascent (i.e., hydrometeors are retained within the parcel during the first few kilometers of ascent), regardless of the initiation method, microphysics scheme, vertical wind shear, or horizontal grid spacing. This suggests that when determining the inflow layer, the physically relevant way to compute CIN is using a reversible moist adiabatic process instead of a pseudoadiabatic process, because CIN is typically accumulated over the lowest few kilometers of parcel ascent.
Passive tracers were used to probe the origins of updraft air in the simulations. When the convection initiation method was weaker, parcels with large amounts of RCIN were unable to participate in the midlevel updraft in large quantities, despite the fact that these parcels possessed nonzero CAPE and PCIN $<15 \mathrm{~J} \mathrm{~kg}^{-1}$. When these simulations were rerun without hydrometeor loading, simulations employing weaker initiation methods were able to ingest relatively more air (compared to other levels) from the lowest $500 \mathrm{~m}$ into their midlevel updrafts, which further highlights the role of hydrometeor loading in influencing the inflow layer. These results agree with those from the updraft parcel analysis that RCIN, not PCIN, is the physically relevant quantity that should be used when determining the inflow layer. Finally, the updraft forcing was also found to play an important role in modulating the inflow layer, with simulations utilizing stronger updraft forcings ingesting larger fractions of air with considerable RCIN.

One major implication of these results is that convective storms may have inflow-layer bases that lie several hundred 


\section{0-45 min, 5.988-km Updraft}

a) LLC

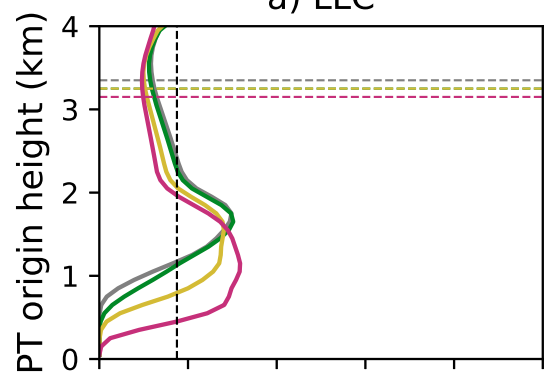

d) U10

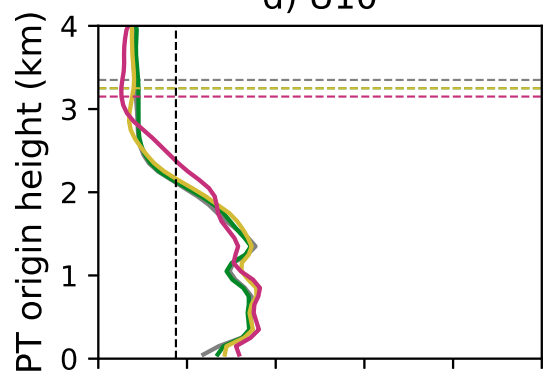

g) $\mathrm{B} 4 \mathrm{CRHZO}$

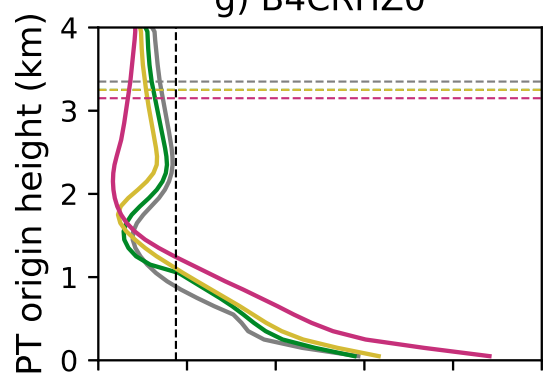

k) 57.5

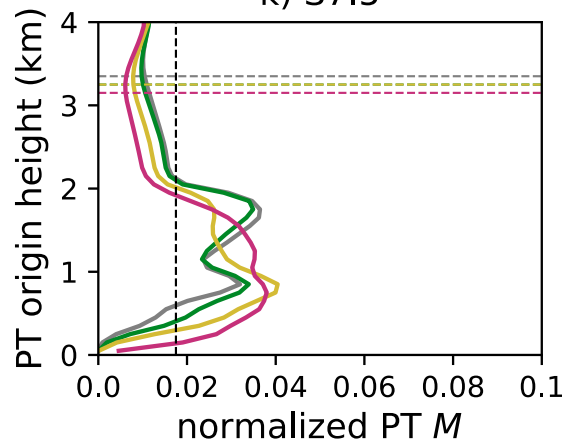

b) LLC2

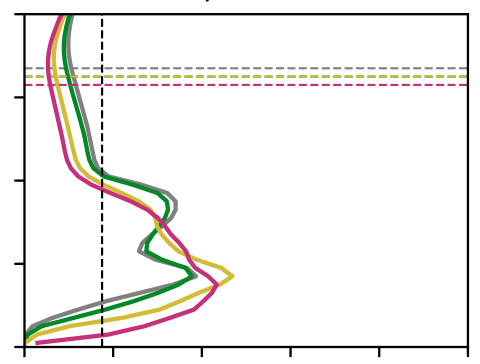

e) B2

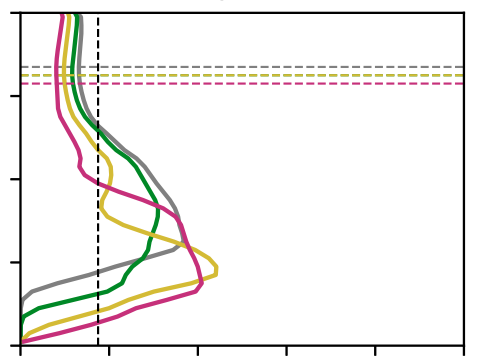

i) NSSL

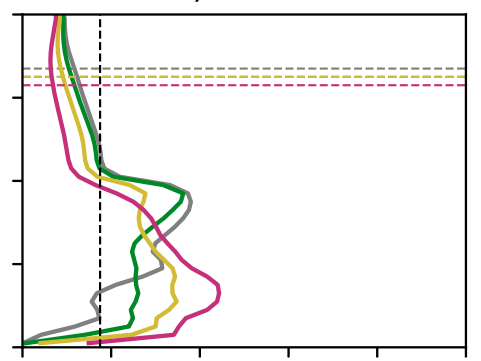

I) $\mathrm{S} 15$

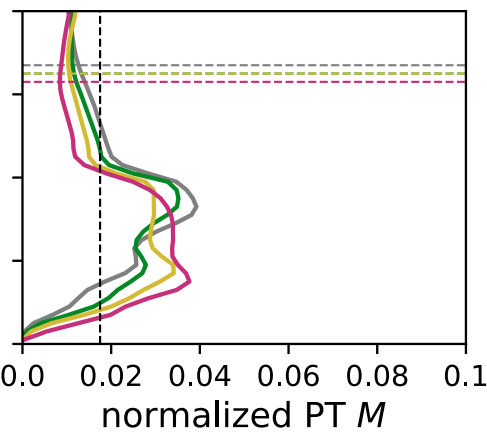

c) U5

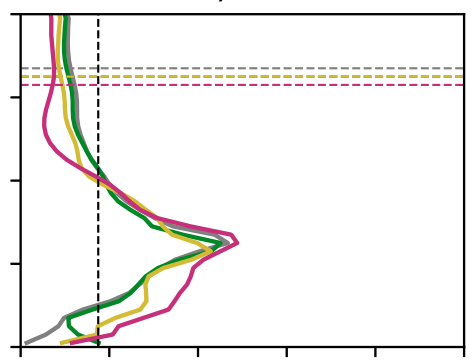

f) $\mathrm{B} 2 \mathrm{CRH}$

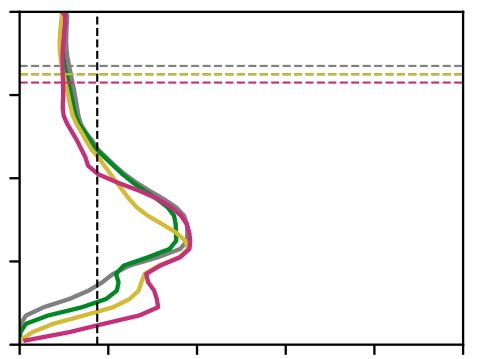

j) AUT

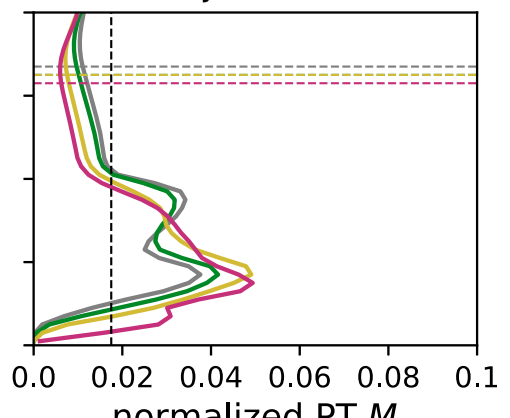

normalized PT $M$

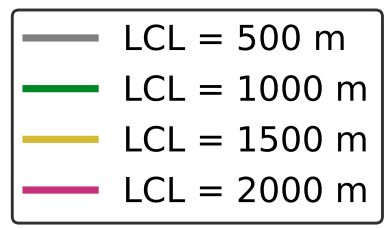

FIG. 12. Normalized passive tracer $M$ values computed using the 5.988-km updraft over the first 45 min. The $M$ values are normalized using the sum of the $M$ values from all 72 passive tracers. Dashed colored lines denote the top of the layer where PCAPE $\geq 100 \mathrm{~J} \mathrm{~kg}^{-1}$ (note that the LCL $=1000$ - and 1500-m lines perfectly overlap). Dashed black line denotes the normalized $M$ value of 0.0175 (the subjective threshold for the inflow layer).

meters above the surface if parcels in the lowest levels of the environment have large RCIN. This raising of the inflow layer base owing to substantial RCIN is most likely in low-LCL, high-LFC environments, and can occur even if there is substantial surface-based CAPE. This last point is particularly important because it implies that some environments may spawn elevated storms even if there is surface-based CAPE. These changes to the inflow layer 


\section{0-45 min, 5.988-km Updraft}

a) LLC

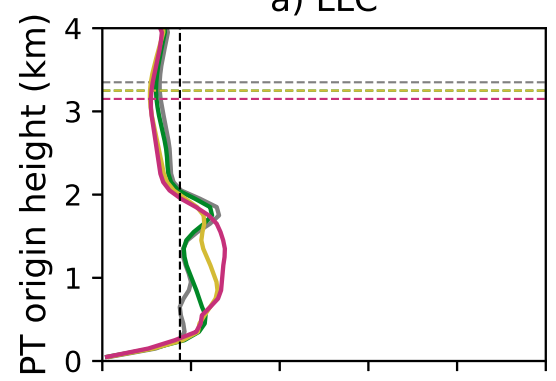

d) $U 10$

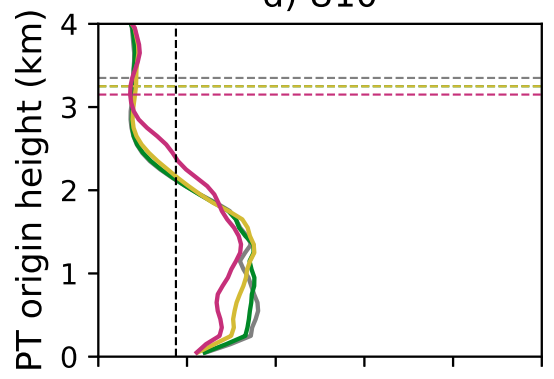

g) $\mathrm{B} 4 \mathrm{CRHZO}$

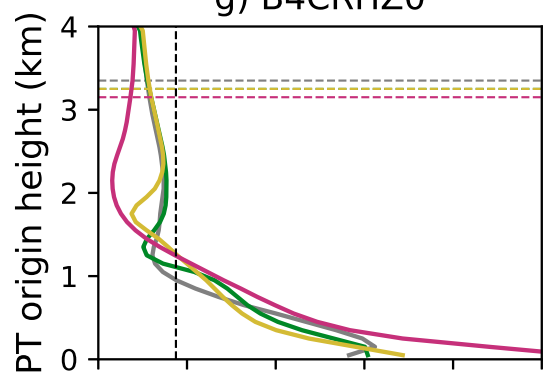

k) 57.5

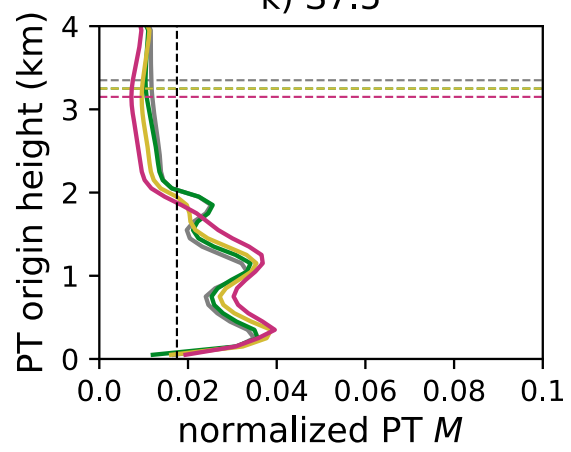

b) LLC2

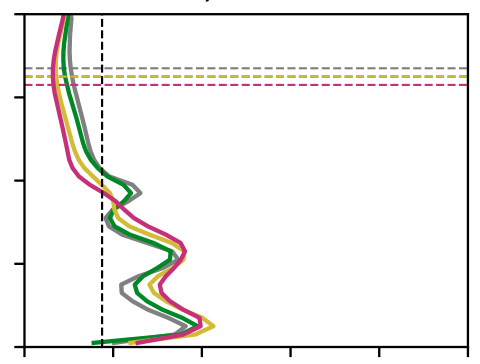

e) B2

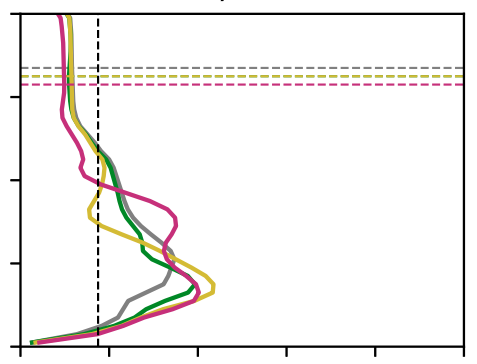

i) NSSL

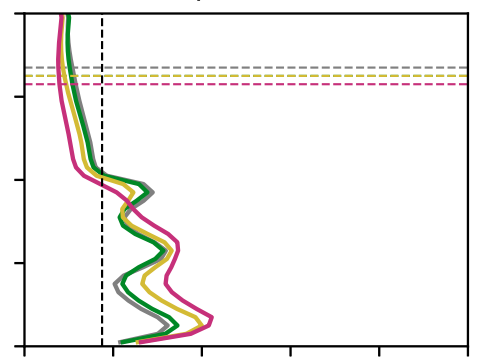

l) $\mathrm{S} 15$

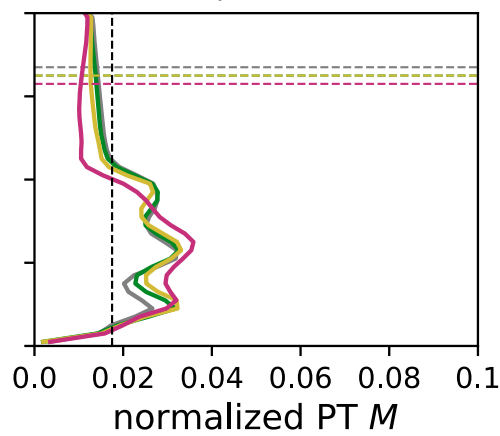

c) U5

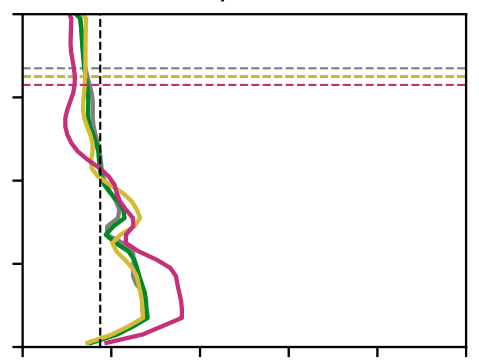

f) $\mathrm{B} 2 \mathrm{CRH}$

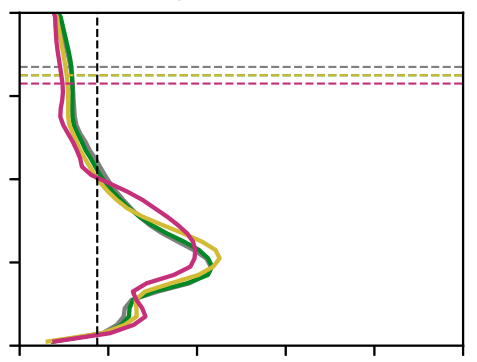

j) $\mathrm{AUT}$

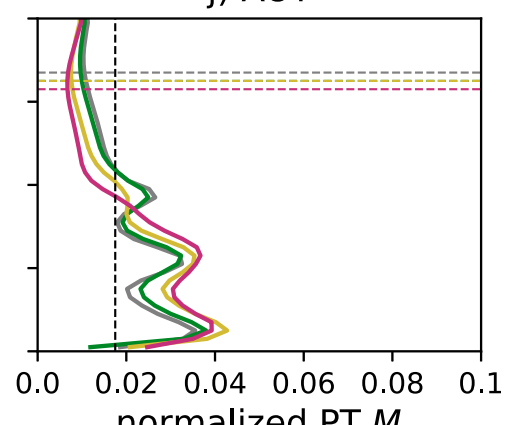

normalized PT $M$

FIG. 13. As in Fig. 12, but for simulations that neglect hydrometeor loading in the vertical momentum equation.

are important because the inflow layer determines which parcels are ingested by the storm, which directly influences storm behavior.

Additional work is needed to explore the robustness of our results and determine if forecasters would benefit from examining RCIN instead of PCIN. To this end, other storm modes with stronger updraft forcings, such as squall lines and supercells, should be examined to see if parcel ascent in the lowest few kilometers of these storm modes best matches a pseudoadiabatic or reversible moist adiabatic process. The inflow layers of these other storm modes should also be interrogated to determine whether the inflow layer base is raised in cases where low-level parcels possess significant RCIN (but still have positive PCAPE 
0-45 $\min , 6.05-\mathrm{km}$ Updraft

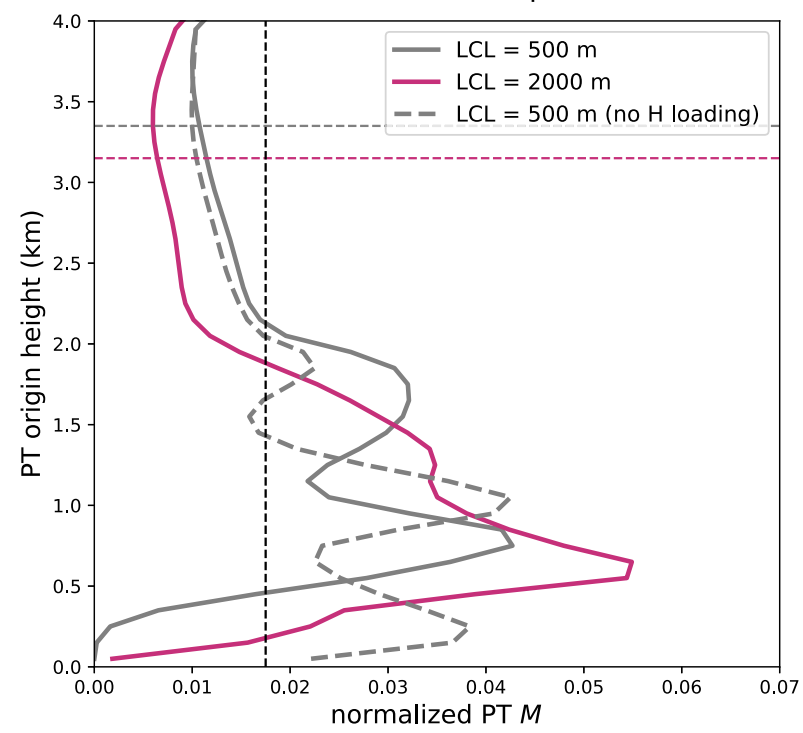

FIG. 14. As in Fig. 12, but for simulations using 100-m grid spacing and the LLC2 initiation method. LCLs are denoted in the legend and the simulation represented with the gray dashed line neglects hydrometeor loading in the vertical momentum equation.

and minimal PCIN). It seems likely that the strong vertical perturbation pressure gradient accelerations associated with a mature supercell or squall line will cause the storm to ingest more parcels with substantial RCIN, but the majority of parcels participating in the inflow layer may still possess minimal RCIN (such parcels would be easier to lift, and, therefore, be more likely to contribute to the midlevel updraft). Finally, it may be fruitful to reexamine the proximity sounding study of Thompson et al. (2007) to see if using RCIN instead of PCIN when computing the EIL, or adding kinematic quantities related to the updraft forcing to the EIL (as suggested by Nowotarski et al. 2020), improves the ability of EIL-derived quantities to differentiate between environments associated with various storm modes and storm hazards.

Acknowledgments. The authors thank George Bryan for all the work he has done to develop and maintain CM1. The three anonymous reviewers are also thanked for their careful reviews that substantially improved the quality of this article. Simulations were performed on the Penn State Institute for Computational and Data Science Roar supercomputer. Data analysis was conducted using the NumPy, SciPy, XArray, Matplotlib, and Metpy (May et al. 2021) packages in Python. This material is based upon work supported by a Pennsylvania State University Graduate Fellowship and the National Science Foundation (NSF) Graduate Research Fellowship Program under Grant DGE1255832. PMM and YPR acknowledge support from NSF Grant AGS-1821885 and MRK acknowledges support from NSF Grant AGS-1855063. Any opinions, findings, and conclusions or recommendations expressed in this material are those of the authors and do not necessarily reflect the views of the NSF.

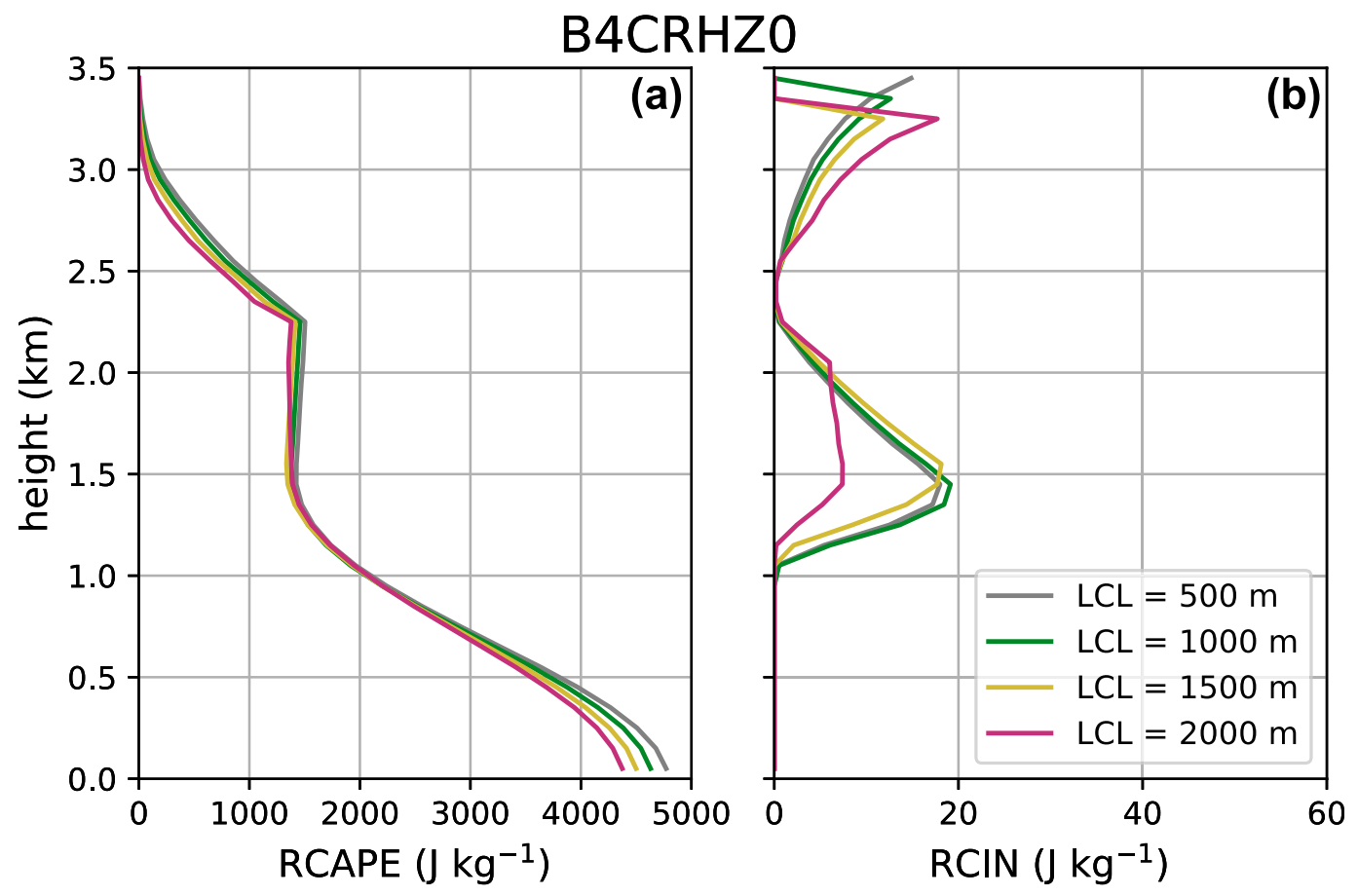

FIG. 15. Reversible thermodynamic parameters for parcels lifted from the height indicated on the $y$ axis in the simulations using the B4CRHZ0 initiation method. (a) RCAPE and (b) RCIN, with the different colored lines corresponding to different initial base states. Thermodynamic parameters are computed using the getcape subroutine in $\mathrm{CM} 1$ and use profiles taken from the center of the initiating warm bubble. 
Data availability statement. CM1 source code, namelist files, and analysis code are available to the public at the Penn State Data Commons website (https://doi.org/10.26208/24tp-m226). Python code to compute pseudoadiabatic and reversible sounding parameters can also be found on GitHub at https:// github.com/ShawnMurd/MetAnalysis.

\section{REFERENCES}

Benjamin, S. G., and Coauthors, 2004: An hourly assimilation-forecast cycle: The RUC. Mon. Wea. Rev., 132, 495-518, https://doi.org/ 10.1175/1520-0493(2004)132<0495:AHACTR > 2.0.CO;2.

Betts, A. K., 1982: Saturation point analysis of moist convective overturning. J. Atmos. Sci., 39, 1484-1505, https://doi.org/ 10.1175/1520-0469(1982)039<1484:SPAOMC >2.0.CO;2.

Bohren, C. F., and B. A. Albrecht, 1998: Atmospheric Thermodynamics. Oxford University Press, 402 pp.

Bryan, G. H., and J. M. Fritsch, 2002: A benchmark simulation for moist nonhydrostatic numerical models. Mon. Wea. Rev., 130, 2917-2928, https://doi.org/10.1175/1520-0493(2002)130<2917: ABSFMN $>2.0 . \mathrm{CO} ; 2$.

- , and H. Morrison, 2012: Sensitivity of a simulated squall line to horizontal resolution and parameterization of microphysics. Mon. Wea. Rev., 140, 202-225, https://doi.org/10.1175/MWRD-11-00046.1.

— J. C. Wyngaard, and J. M. Fritsch, 2003: Resolution requirements for the simulation of deep moist convection. Mon. Wea. Rev., 131, 2394-2416, https://doi.org/10.1175/15200493(2003)131<2394:RRFTSO>2.0.CO;2.

Bunkers, M. J., B. A. Klimowski, J. W. Zeitler, R. L. Thompson, and M. L. Weisman, 2000: Predicting supercell motion using a new hodograph technique. Wea. Forecasting, 15, 61-79, https://doi.org/10.1175/1520-0434(2000)015<0061:PSMUAN > 2.0.CO;2.

Coffer, B. E., M. D. Parker, R. L. Thompson, B. T. Smith, and R. E. Jewell, 2019: Using near-ground storm relative helicity in supercell tornado forecasting. Wea. Forecasting, 34, 1417-1435, https://doi.org/10.1175/WAF-D-19-0115.1.

_ M. Taszarek, and M. D. Parker, 2020: Near-ground wind profiles of tornadic and nontornadic environments in the United States and Europe from ERA5 reanalyses. Wea. Forecasting, 35, 2621-2638, https://doi.org/10.1175/WAF-D-20-0153.1.

Cohen, C., and W. M. Frank, 1989: A numerical study of lapse-rate adjustments in the tropical atmosphere. Mon. Wea. Rev., 117, 1891-1905, https://doi.org/10.1175/1520-0493(1989)117<1891: ANSOLR $>2.0 . \mathrm{CO} ; 2$.

Davies, J. M., 2004: Estimations of CIN and LFC associated with tornadic and nontornadic supercells. Wea. Forecasting, 19, 714-726, https://doi.org/10.1175/1520-0434(2004)019<0714: EOCALA $>2.0 . \mathrm{CO} ; 2$.

Doswell, C. A., III, and E. N. Rasmussen, 1994: The effect of neglecting the virtual temperature correction on CAPE calculations. Wea. Forecasting, 9, 625-629, https://doi.org/10.1175/ 1520-0434(1994)009<0625:TEONTV>2.0.CO;2.

Emanuel, K. A., 1994: Atmospheric Convection. Oxford University Press, $580 \mathrm{pp}$.

Gray, K., and J. Frame, 2019: Investigating the transition from elevated multicellular convection to surface-based supercells during the tornado outbreak of 24 August 2016 using a WRF Model simulation. Wea. Forecasting, 34, 1051-1079, https:// doi.org/10.1175/WAF-D-18-0209.1.

Kirkpatrick, C., E. W. McCaul, and C. Cohen, 2009: Variability of updraft and downdraft characteristics in a large parameter space study of convective storms. Mon. Wea. Rev., 137, 1550-1561, https://doi.org/10.1175/2008MWR2703.1.

Klemp, J. B., and R. B. Wilhelmson, 1978: The simulation of threedimensional convective storm dynamics. J. Atmos. Sci., 35, 1070-1096, https://doi.org/10.1175/1520-0469(1978)035<1070: TSOTDC $>2.0 . C O ; 2$.

Lamb, D., and J. Verlinde, 2011: Physics and Chemistry of Clouds. Cambridge University Press, 584 pp.

Loftus, A. M., D. B. Weber, I. Doswell, and A. Charles, 2008: Parameterized mesoscale forcing mechanisms for initiating numerically simulated isolated multicellular convection. Mon. Wea. Rev., 136, 2408-2421, https://doi.org/10.1175/ 2007MWR2133.1.

Mansell, E. R., C. L. Ziegler, and E. C. Bruning, 2010: Simulated electrification of a small thunderstorm with two-moment bulk microphysics. J. Atmos. Sci., 67, 171-194, https://doi.org/10.1175/ 2009JAS2965.1.

May, R. M., S. C. Arms, P. Marsh, E. Bruning, J. R. Leeman, K. Goebbert, J. E. Thielen, and Z. S. Bruick, 2021: Metpy: A Python package for meteorological data. Accessed 10 August 2020, https://github.com/Unidata/MetPy.

McCaul, E. W., Jr., and M. L. Weisman, 2001: The sensitivity of simulated supercell structure and intensity to variations in the shapes of environmental buoyancy and shear profiles. Mon. Wea. Rev., 129, 664-687, https://doi.org/10.1175/15200493(2001)129<0664:TSOSSS > 2.0.CO;2.

, and C. Cohen, 2002: The impact on simulated storm structure and intensity of variations in the mixed layer and moist layer depths. Mon. Wea. Rev., 130, 1722-1748, https://doi.org/ 10.1175/1520-0493(2002)130<1722:TIOSSS>2.0.CO;2.

,--1 , and C. Kirkpatrick, 2005: The sensitivity of simulated storm structure, intensity, and precipitation efficiency to environmental temperature. Mon. Wea. Rev., 133, 3015-3037, https://doi.org/10.1175/MWR3015.1.

Molinari, J., D. M. Romps, D. Vollaro, and L. Nguyen, 2012: CAPE in tropical cyclones. J. Atmos. Sci., 69, 2452-2463, https:// doi.org/10.1175/JAS-D-11-0254.1.

Morrison, H., J. A. Curry, and V. I. Khvorostyanov, 2005: A new double-moment microphysics parameterization for application in cloud and climate models. Part I: Description. J. Atmos. Sci., 62, 1665-1677, https://doi.org/10.1175/JAS3446.1.

_ - G. Thompson, and V. Tatarskii, 2009: Impact of cloud microphysics on the development of trailing stratiform precipitation in a simulated squall line: Comparison of one- and two-moment schemes. Mon. Wea. Rev., 137, 991-1007, https://doi.org/10.1175/ 2008MWR2556.1.

_- A. Morales, and C. Villanueva-Birriel, 2015: Concurrent sensitivities of an idealized deep convective storm to parameterization of microphysics, horizontal grid resolution, and environmental static stability. Mon. Wea. Rev., 143, 20822104, https://doi.org/10.1175/MWR-D-14-00271.1.

Naylor, J., and M. S. Gilmore, 2012: Convective initiation in an idealized cloud model using an updraft nudging technique. Mon. Wea. Rev., 140, 3699-3705, https://doi.org/10.1175/MWRD-12-00163.1.

NCDC, 2011: Storm data and unusual weather phenomena with late reports and corrections. Accessed 20 May 2021, https:// www.ncdc.noaa.gov/stormevents/.

Nowotarski, C. J., P. M. Markowski, and Y. P. Richardson, 2011: The characteristics of numerically simulated supercell storms situated over statically stable boundary layers. Mon. Wea. Rev., 139, 3139-3162, https://doi.org/10.1175/MWR-D-10-05087.1.

_- J. M. Peters, and J. P. Mulholland, 2020: Evaluating the effective inflow layer of simulated supercell updrafts. Mon. 
Wea. Rev., 148, 3507-3532, https://doi.org/10.1175/MWRD-20-0013.1.

Parker, M. D., 2008: Response of simulated squall lines to low-level cooling. J. Atmos. Sci., 65, 1323-1341, https://doi.org/10.1175/ 2007JAS2507.1.

Peters, J. M., C. J. Nowotarski, and H. Morrison, 2019: The role of vertical wind shear in modulating maximum supercell updraft velocities. J. Atmos. Sci., 76, 3169-3189, https://doi.org/10.1175/ JAS-D-19-0096.1.

,-- , and G. L. Mullendore, 2020: Are supercells resistant to entrainment because of their rotation? J. Atmos. Sci., 77, 1475-1495, https://doi.org/10.1175/JAS-D-19-0316.1.

Rasmussen, E. N., and D. O. Blanchard, 1998: A baseline climatology of sounding-derived supercell and tornado forecast parameters. Wea. Forecasting, 13, 1148-1164, https://doi.org/ 10.1175/1520-0434(1998)013<1148:ABCOSD > 2.0.CO;2.

Richardson, Y. P., 1999: The influence of horizontal variations in vertical shear and low-level moisture on numerically simulated convective storms. Ph.D. thesis, University of Oklahoma, $236 \mathrm{pp}$.

Taszarek, M., J. T. Allen, T. Púčik, K. A. Hoogewind, and H. E. Brooks, 2020: Severe convective storms across Europe and the United States. Part II: ERA5 environments associated with lightning, large hail, severe wind, and tornadoes. J. Climate, $\mathbf{3 3 ,}$ 10263-10 286, https://doi.org/10.1175/JCLI-D-20-0346.1.

Thompson, R. L., R. Edwards, J. A. Hart, K. L. Elmore, and P. Markowski, 2003: Close proximity soundings within supercell environments obtained from the Rapid Update Cycle.
Wea. Forecasting, 18, 1243-1261, https://doi.org/10.1175/15200434(2003)018<1243:CPSWSE > 2.0.CO;2.

- C. M. Mead, and R. Edwards, 2007: Effective storm-relative helicity and bulk shear in supercell thunderstorm environments. Wea. Forecasting, 22, 102-115, https://doi.org/10.1175/ WAF969.1.

—, B. T. Smith, A. R. Dean, and P. T. Marsh, 2013: Spatial distribution of tornadic near-storm environments by convective mode. Electron. J. Severe Storms Meteor., 8 (5), https:// ejssm.org/ojs/index.php/ejssm/article/viewArticle/125.

Warren, R. A., H. Richter, H. A. Ramsay, S. T. Siems, and M. J. Manton, 2017: Impact of variations in upper-level shear on simulated supercells. Mon. Wea. Rev., 145, 2659-2681, https:// doi.org/10.1175/MWR-D-16-0412.1.

Wei, D., A. M. Blyth, and D. J. Raymond, 1998: Buoyancy of convective clouds in TOGA COARE. J. Atmos. Sci., 55, 3381-3391, https://doi.org/10.1175/1520-0469(1998)055<3381: BOCCIT>2.0.CO;2.

Weisman, M. L., and J. B. Klemp, 1984: The structure and classification of numerically simulated convective storms in directionally varying wind shears. Mon. Wea. Rev., 112, 2479-2498, https://doi.org/10.1175/1520-0493(1984)112<2479:TSACON > 2.0.CO;2.

Xu, K.-M., and K. A. Emanuel, 1989: Is the tropical atmosphere conditionally unstable? Mon. Wea. Rev., 117, 1471-1479, https://doi.org/10.1175/1520-0493(1989)117<1471:ITTACU> 2.0.CO;2. 